\title{
The monsoon system: Land-sea breeze or the ITCZ?
}

\author{
SulOchana GadGil \\ Centre for Atmospheric $\& 3$ Oceanic Sciences, Indian Institute of Science, Bengaluru 560 012, India. \\ e-mail: sulugadgil@gmail.com
}

MS received 15 May 2017; revised 30 August 2017; accepted 31 August 2017; published online 27 January 2018

For well over 300 years, the monsoon has been considered to be a gigantic land-sea breeze driven by the land-ocean contrast in surface temperature. In this paper, this hypothesis and its implications for the variability of the monsoon are discussed and it is shown that the observations of monsoon variability do not support this popular theory of the monsoon. An alternative hypothesis (whose origins can be traced to Blanford's (1886) remarkably perceptive analysis) in which the basic system responsible for the Indian summer monsoon is considered to be the Intertropical Convergence Zone (ITCZ) or the equatorial trough, is then examined and shown to be consistent with the observations. The implications of considering the monsoon as a manifestation of the seasonal migration of the ITCZ for the variability of the Indian summer monsoon and for identification of the monsoonal regions of the world are briefly discussed.

Keywords. Indian summer monsoon; monsoonal regions; intertropical convergence zone; equatorial trough; heat lows.

\section{Introduction}

The word 'monsoon' is derived from the Arabic/ Hindi word 'mausam' for season and the most important characteristic of the monsoon is the large seasonal variation in the winds and rainfall. Traditionally, monsoonal regions have been identified on the basis of seasonal variation in the direction of the surface winds (Ramage 1971). The mean surface winds for January and July are depicted in figure 1 , in which the monsoonal region delineated by Ramage (1971) is also shown. It is seen that the Indian region and the surrounding seas are near the centre of the monsoonal region so defined. However, for the teeming millions residing in the Indian region, the seasonal variation of rainfall (figure 2) is far more important than that of the direction of the winds, and in common parlance, the word monsoon refers to the system that gives rainfall in the rainy season. The onset of the monsoon occurs over the southwestern tip of the Indian peninsula around the beginning of June and the monsoon retreats from there in December (figure 3). The period June-December, when the Indian region is under the sway of the monsoon, is divided into two seasons: the summer monsoon from June to September (or the so-called southwest monsoon because the surface winds are from the southwest, figure 4) and the post-monsoon from October to December (or the northeast monsoon because the surface winds are from the northeast, figure 4). Most of the studies of the Indian monsoon have been on the summer monsoon which contributes about $80 \%$ of the annual rainfall over the Indian region (figure 2). I shall also focus on the Indian summer monsoon in this paper and refer to it as 'the monsoon'.

The major rain-belt in the mean rainfall pattern for the summer monsoon (figure 5) is over the monsoon zone north of about $20^{\circ} \mathrm{N}$. During 

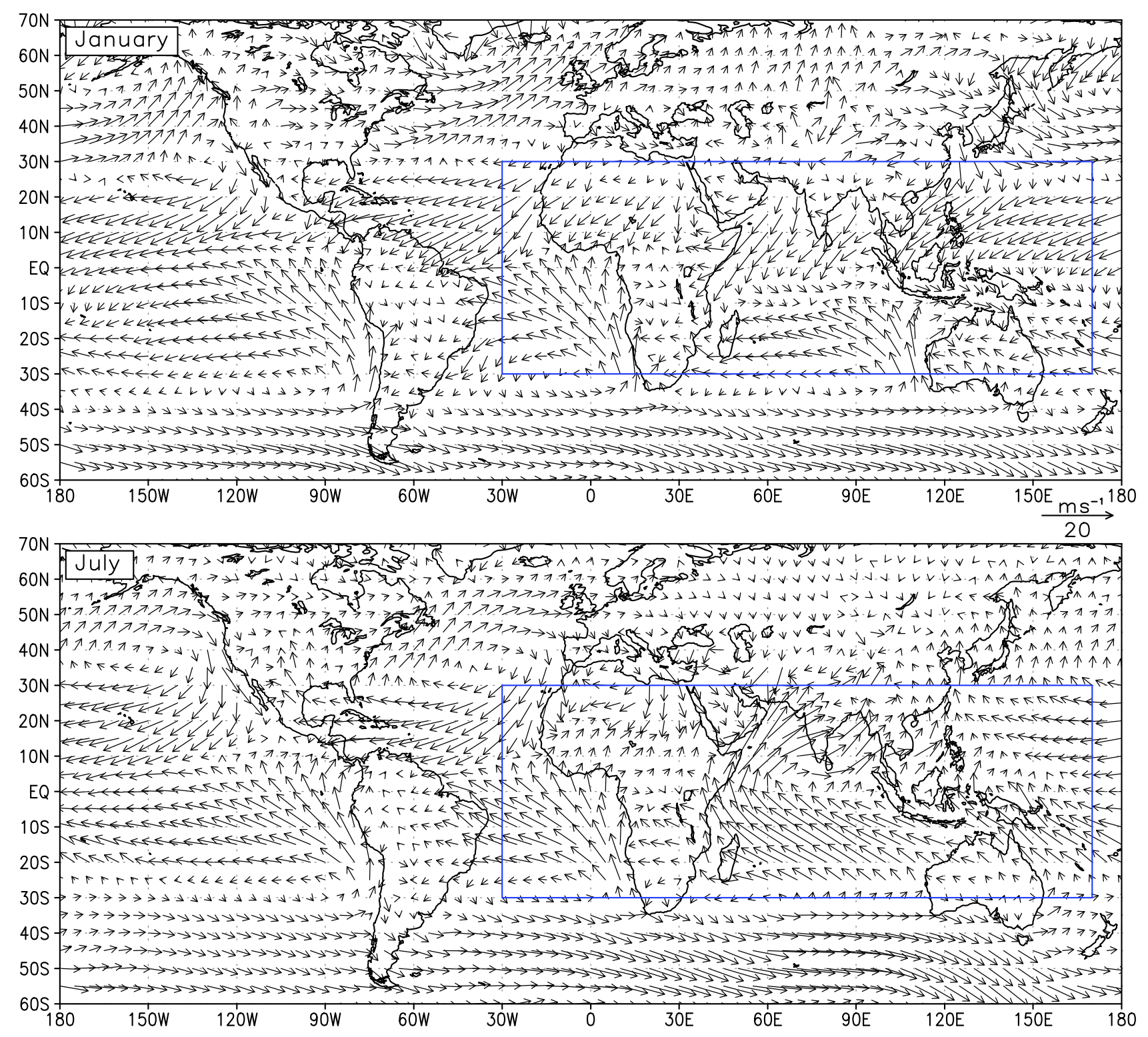

Figure 1. Mean surface winds in January and July (from NCEP reanalysis data); the limit of the monsoonal regions of the world as identified by Ramage (1971) is indicated in blue.

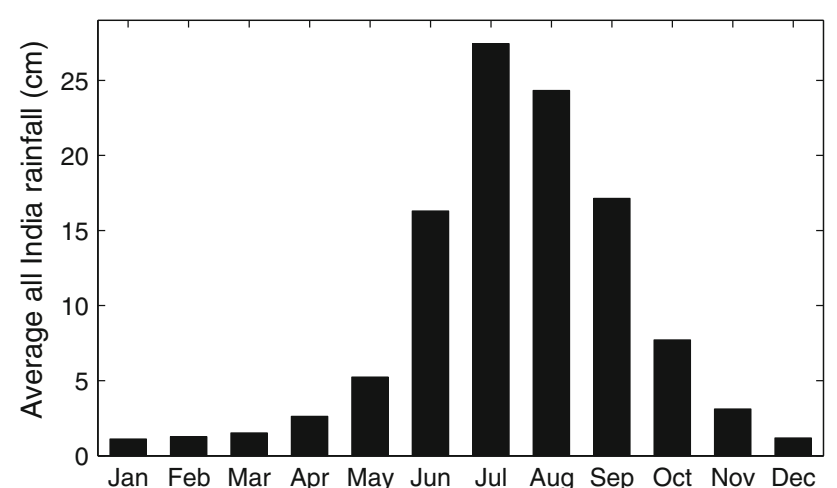

Figure 2. Mean monthly rainfall $(\mathrm{cm})$ over the Indian region based on IMD grid data (Rajeevan et al. 2006). the summer monsoon, high rainfall also occurs over the hilly regions of the west coast of the peninsula and the north-eastern parts of India (figure 5). The most important feature of the monsoon is its reliability. The Indian region gets monsoon rainfall year after year, without fail. If we consider the interannual variation of the rainfall averaged over the Indian region during the summer monsoon, i.e., Indian summer monsoon rainfall (ISMR), the standard deviation is only about $10 \%$ of the mean and the largest recorded deficit in the Indian summer monsoon rainfall (ISMR) is less than 3 standard deviations, i.e., less than 30\% (figure 6). 

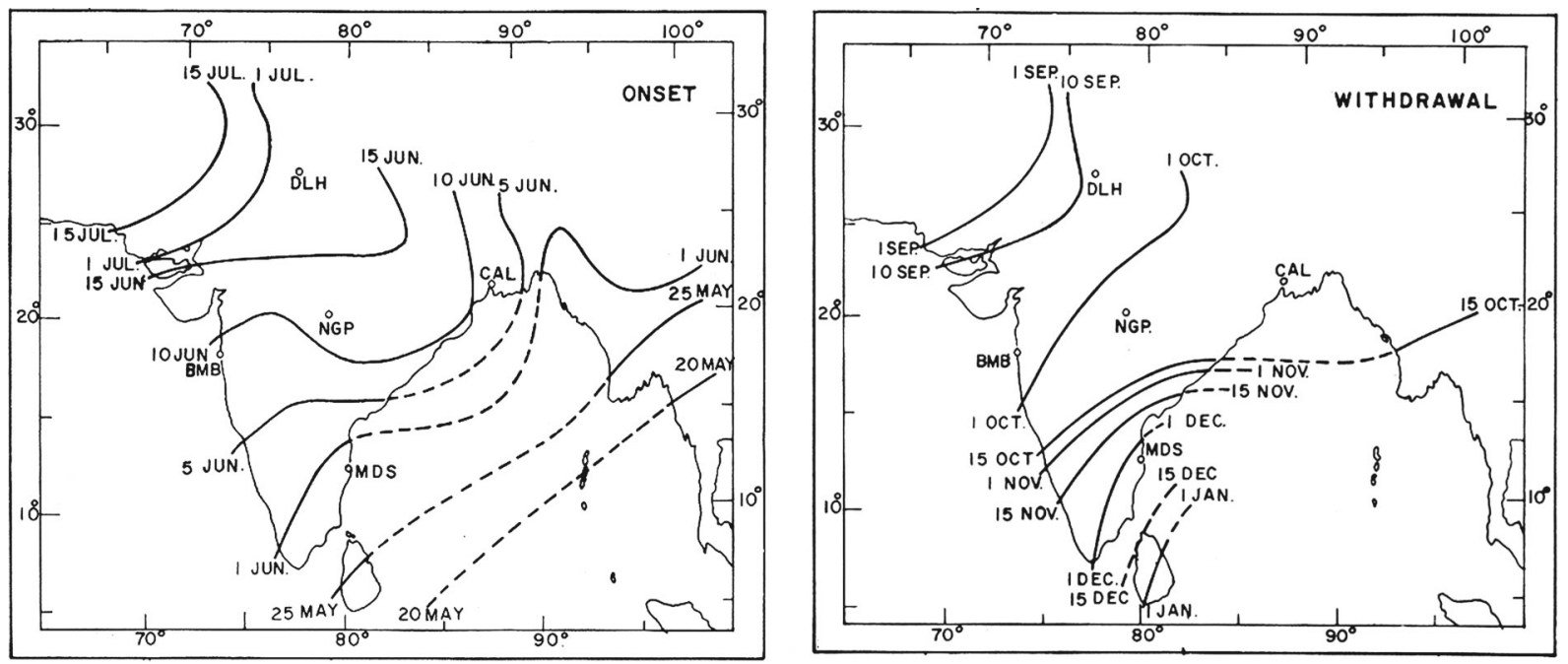

Figure 3. Mean dates of onset and withdrawal of the monsoon (adapted from Rao 1976).
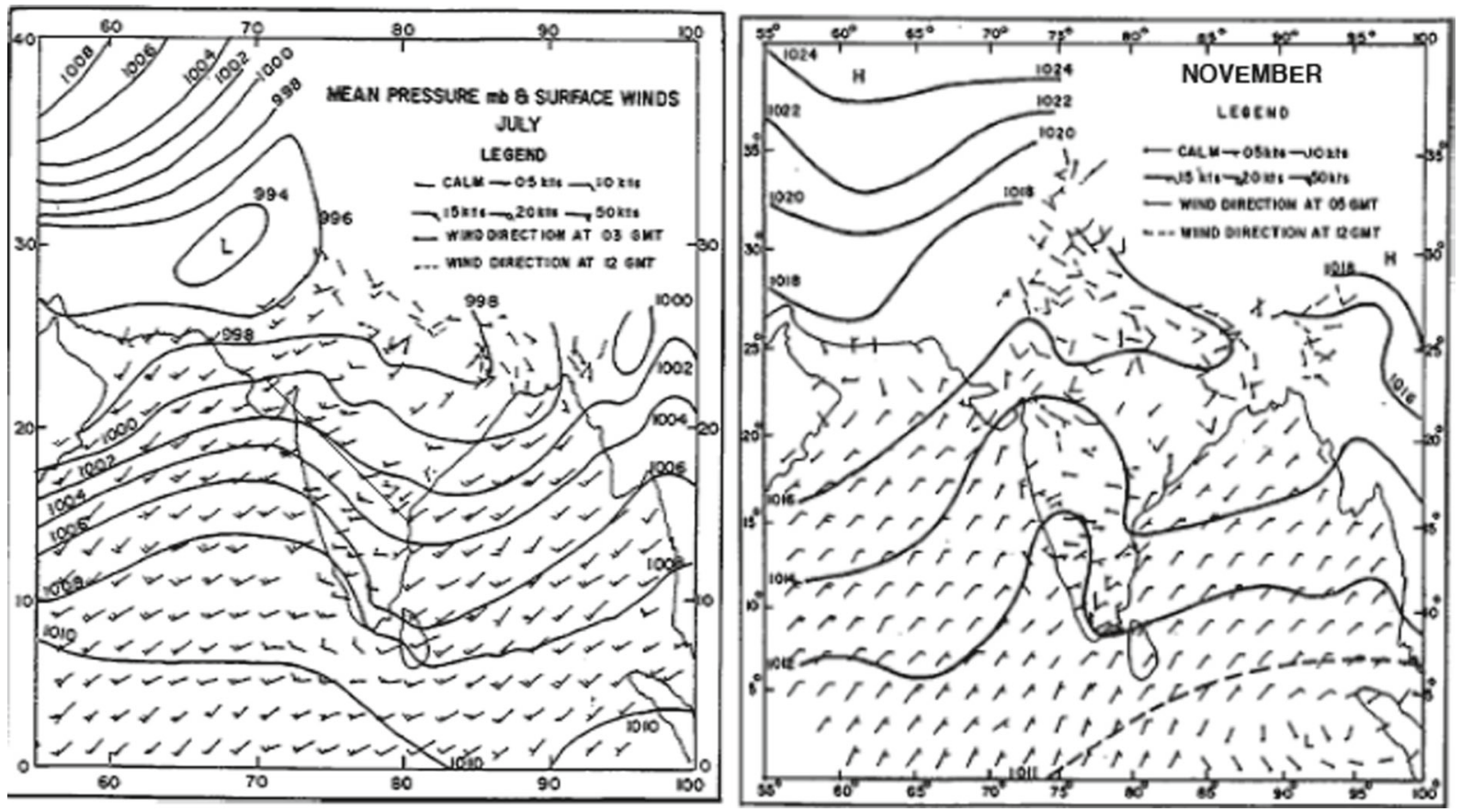

Figure 4. Mean surface pressure and wind over the Indian region for July and November.

Yet, the impact of this variation on the food-grain production and the GDP is large (Gadgil and Gadgil 2006) leading to the Indian Finance Minister commencing the 2011 budget speech with "I seek the blessings of Lord Indra to bestow on us timely and bountiful monsoons". In addition, there is considerable variation in the rainfall within the summer monsoon season, between active spells with substantial rainfall for several days and weak spells with little rainfall (figure 7 ), which also has a large impact on agriculture (Gadgil et al. 2002). Prediction of the variability of the monsoon on different spatio-temporal scales, therefore, assumes great importance. For generating such predictions, a pre-requisite is the understanding of 'how and why' of the variability of the monsoon. This in turn requires the identification of the basic system responsible for the monsoon. In this paper, I address this central problem in monsoon meteorology.

After describing the data analysed in the next section, in section 3 , important facets of the mean patterns of pressure, temperature, circulation and rainfall for the summer monsoon are elucidated. For well over 300 years, the monsoon has been considered to be a gigantic land-sea breeze. In 


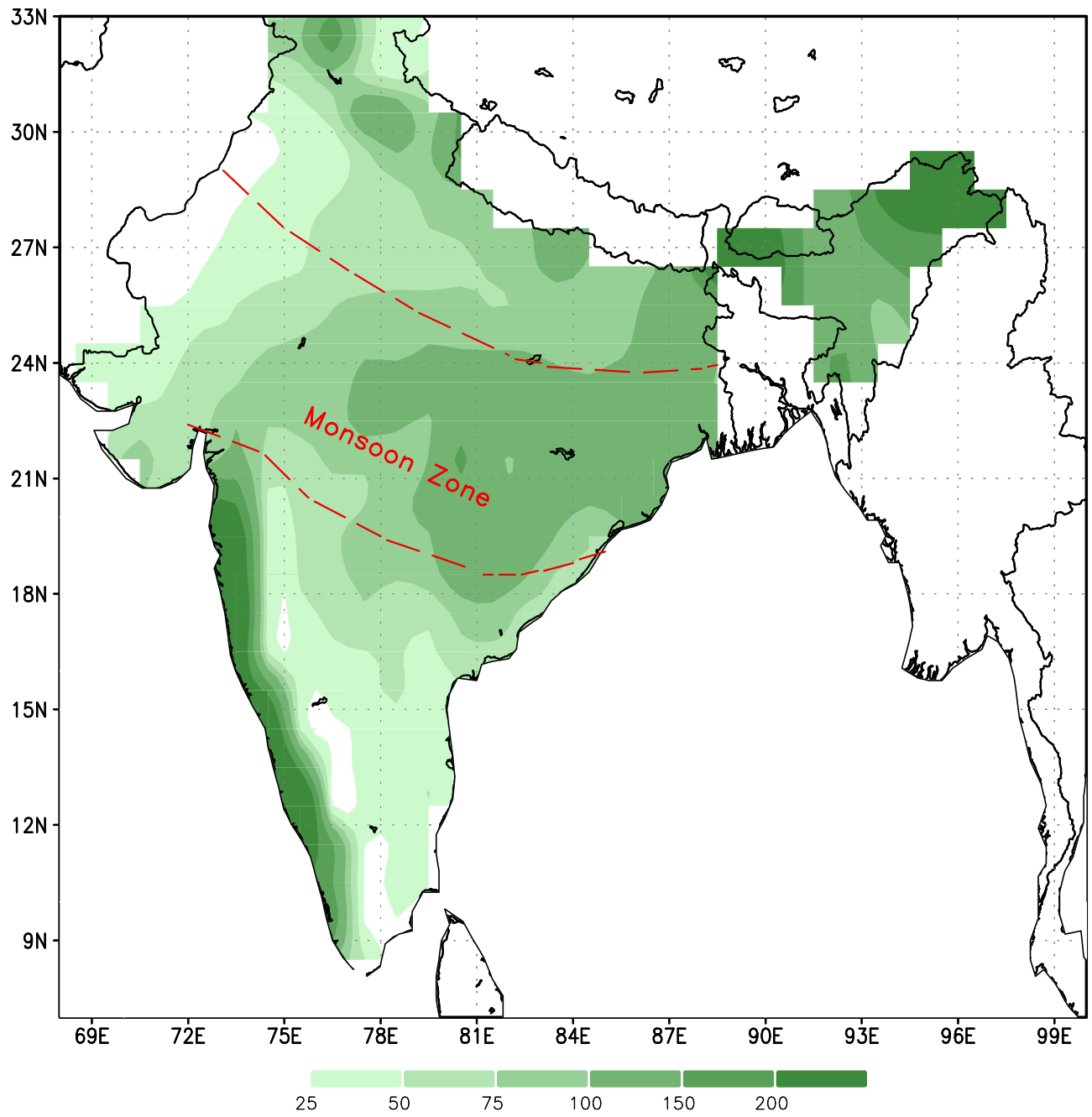

Figure 5. Mean June-September rainfall over the Indian region based on IMD grid data (Rajeevan et al. 2006). The monsoon zone is also indicated.

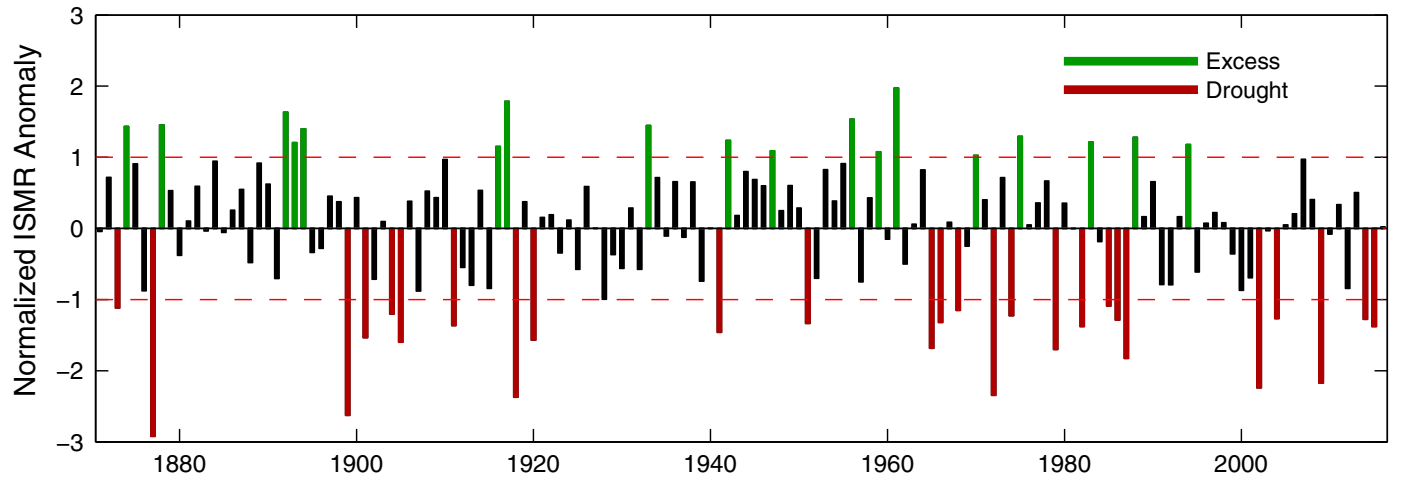

Figure 6. Variation of the anomaly of ISMR, the Indian summer monsoon rainfall (from www.tropmet.res.in, Parthasarathy et al. 1994), normalized by the standard deviation, during 1871-2016. Droughts: normalized ISMR anomaly $<-1.0$ (shown as red bars); excess rainfall seasons: normalized ISMR anomaly $>1.0$ (shown as green bars).

section 4, this hypothesis and its implications for the variability of the monsoon are considered and whether the observations support this popular theory of the monsoon is examined. An alternative hypothesis, whose origins can be traced to Blanford's (1886) remarkably perceptive analysis, in 


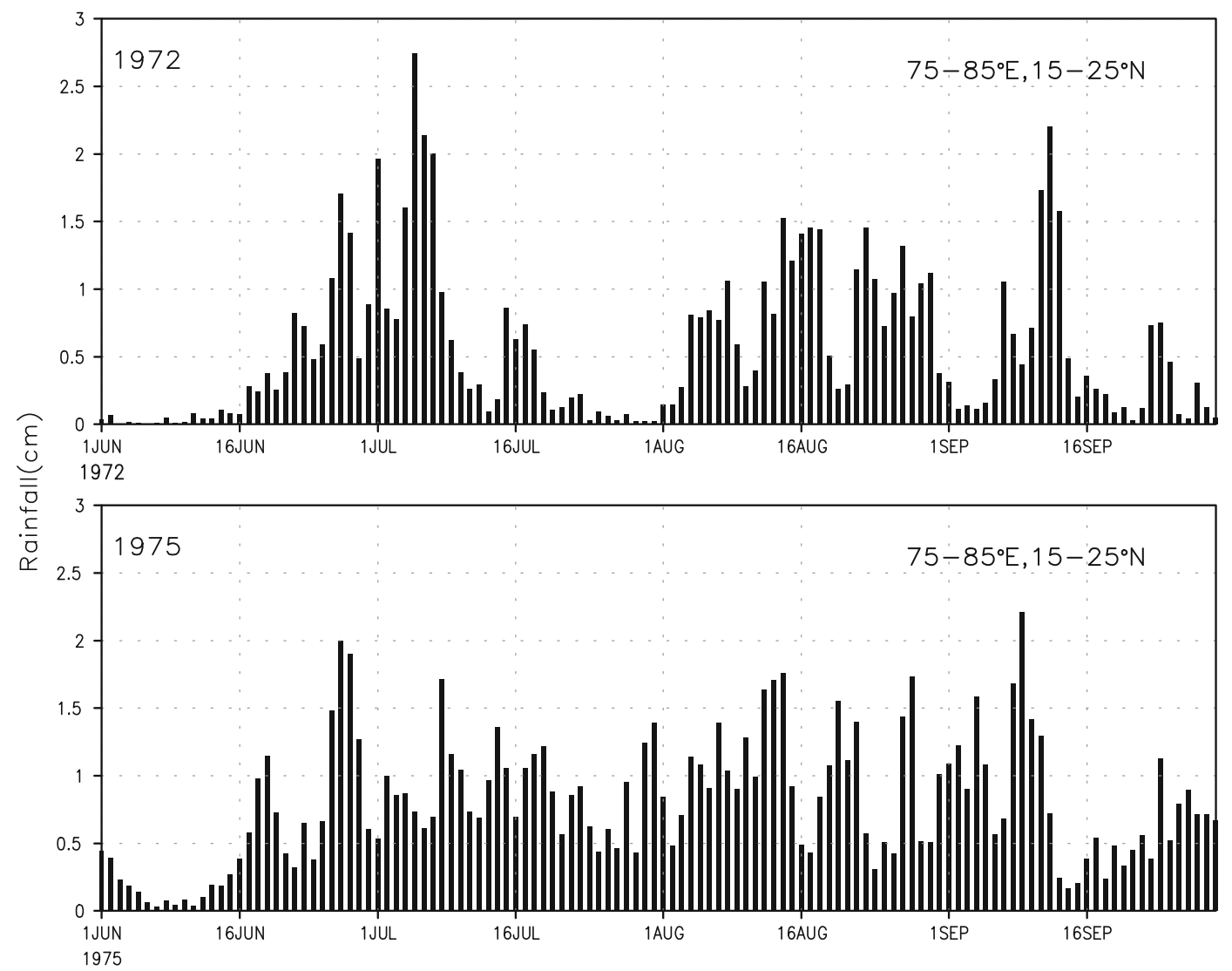

Figure 7. Variation of the daily rainfall averaged over central India $\left(75-85^{\circ} \mathrm{E}, 15-25^{\circ} \mathrm{N}\right)$ derived from IMD grid data $(\mathrm{Rajee}-$ van et al. 2006) during the summer monsoon seasons of the drought of 1972 (ISMR $=65 \mathrm{~cm})$ and excess monsoon season of $1975(\mathrm{ISMR}=96 \mathrm{~cm})$.

which the basic system responsible for the Indian summer monsoon is considered to be the Intertropical Convergence Zone (ITCZ) or the equatorial trough, is discussed in section 5. Section 6 comprises a discussion of divergent tropical circulations, heat lows and the ITCZ, and in section 7, it is shown that the observations are consistent with the hypothesis that the basic system of the monsoon is the ITCZ. In section 8 , the implications of the present understanding of the Indian summer monsoon for its variability are considered; in section 9, the monsoonal regions of the world are delineated on the basis of this understanding and the summary and conclusions are given in section 10 .

\section{Data}

Daily mean gridded rainfall data at a spatial resolution of $1^{\circ} \times 1^{\circ}$ (Rajeevan et al. 2006) and monthly mean gridded surface temperature over the Indian region (Srivastava et al. 2008) available from India Meteorological Department (IMD), monthly mean rainfall data from CPC Merged
Analysis of Precipitation (CMAP, Xie and Arkin 1997), Global Precipitation Climatology Project (GPCP, Adler et al. 2003) taken from https:// www.esrl.noaa.gov/psd/ and daily Outgoing Longwave Radiation (OLR) data obtained from NOAA Earth System Research Laboratory (http://www. esrl.noaa.gov/psd/; Liebmann 1996) are used in this study. Data on surface wind and temperature at $995 \mathrm{hPa}$ from NCEP reanalysis (Kalnay et al. 1996) are also used in this study. The observed monsoon rainfall variability is derived from the all India rainfall available at Indian Institute of Tropical Meteorology (www.tropmet. res.in, Parthasarathy et al. 1994). Sea surface temperature data used here is taken from Hadley Centre (HadISST, Rayner et al. 2003). Atmospheric reanalyses from ECMWF, viz., ERA-40 (Uppala et al. 2005) are also used in this study.

\section{The mean monsoon}

After the onset phase, the summer monsoon gets established over the monsoon zone by the end of 
June and starts retreating from there in September (Ding and Sikka 2006). The peak monsoon months are July and August. Here I consider the important features of the mean patterns of pressure, circulation, temperature and rainfall for the peak monsoon month of July. In the July mean surface pressure pattern (figure 4), it is seen that the lowest surface pressure occurs over the northwestern part around $65^{\circ} \mathrm{E}$ and $30^{\circ} \mathrm{N}$. The surface trough extending southeastward from this point, to the head of the Bay of Bengal around $90^{\circ} \mathrm{E}$ and $20^{\circ} \mathrm{N}$ is generally referred to as the monsoon trough (Rao 1976). The winds to the south of the monsoon trough are southwesterlies and there is a strong shear across the trough with winds with an easterly component to the north (figure 4).

The mean July geopotential height and wind patterns for $850 \mathrm{hPa}$ (figure 8a) shows that the trough location is similar to that at the surface, but the winds have a much stronger zonal component (because of geostrophy), with westerlies south of the trough and easterlies to the north, implying a strong cyclonic vorticity above the boundary layer over the monsoon zone. An important feature of the $850 \mathrm{hPa}$ wind (as well as the surface wind, figure 1) is the strong cross equatorial flow over the western part of the equatorial Indian Ocean arising in response to the large meridional pressure gradient equatorward of the trough over the Indian region. Over the Indian region, the mean July geopotential height pattern for $700 \mathrm{hPa}$ differs markedly from those for the $850 \mathrm{hPa}$ and higher pressures, with the trough not extending to the northwestern part characterized by a marked low at the surface (figure 8b). In the upper troposphere, there is a high pressure belt around $30^{\circ} \mathrm{N}$ stretching across the Indian longitudes (figure 8c), implying a reversal of the north-south pressure gradient from that in the lower atmosphere and easterly winds.

If we consider the average over the Indian longitudes of $70^{\circ}-90^{\circ} \mathrm{E}$, the mean July verticalmeridional circulation (figure 9a) comprises ascent of air over the entire Indian region from $10^{\circ}$ to $30^{\circ} \mathrm{N}$ with strong ascent around $20^{\circ} \mathrm{N}$. The meridional winds are northward in the lower troposphere and southward in the upper troposphere and the circulation is completed by descent of air over the region $10^{\circ}-40^{\circ} \mathrm{S}$. Consistent with the ascent of air, the entire Indian region gets rainfall in July (figure 9b) with the rainfall being particularly high over and
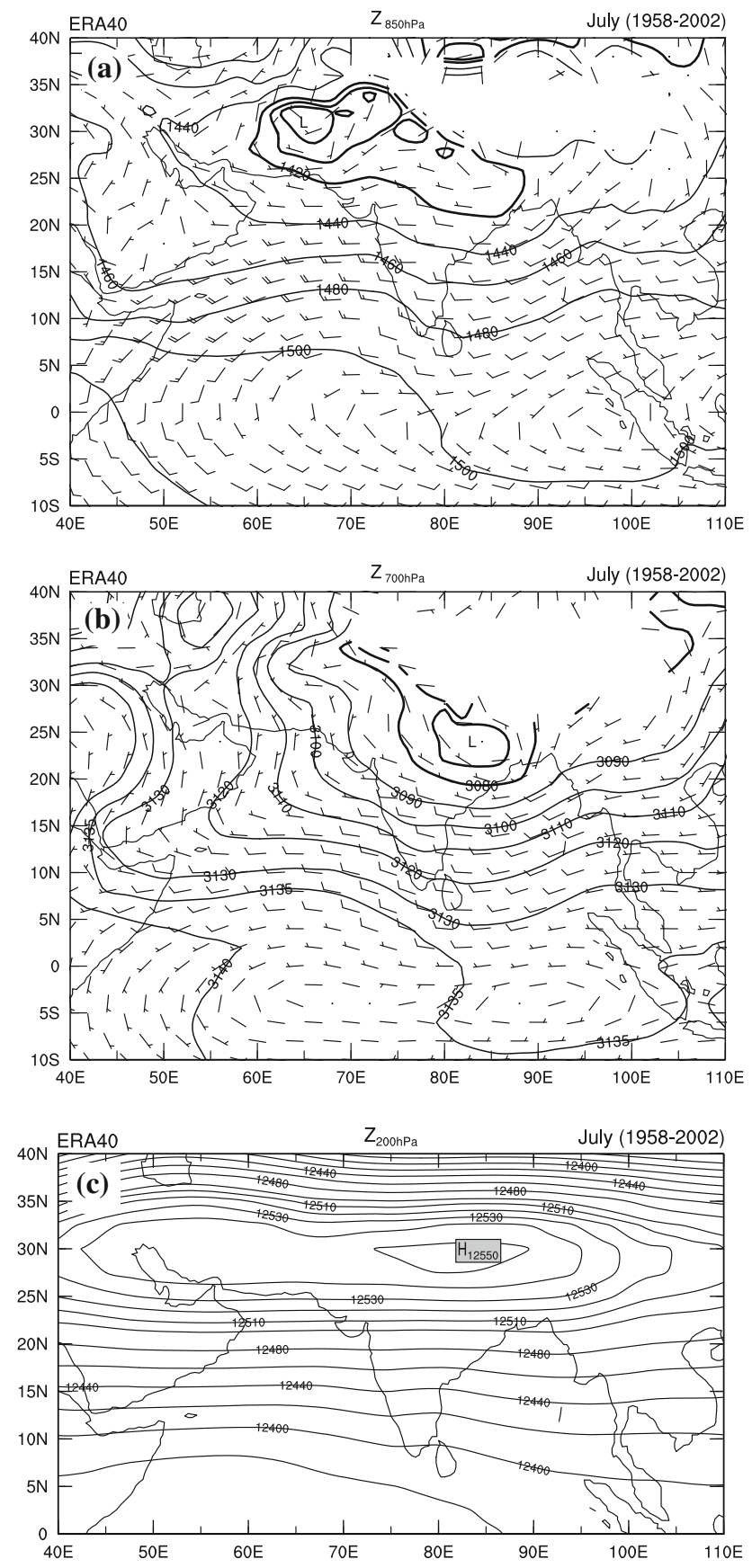

Figure 8. Mean July geopotential heights and winds for (a) $850 \mathrm{hPa}$, (b) $700 \mathrm{hPa}$, and (c) $200 \mathrm{hPa}$ from ERA-40 reanalysis for the period 1958-2002.

along the west coast of the Indian peninsula and northeastern parts of the Indian region. Over the monsoon zone, the rainfall is high over the eastern part, decreases northwestward across the zone and near the northwestern boundary, there is hardly any rain. The surface temperature over land is maximum over the northwestern part of the monsoon zone (figure 10), where there is hardly any 


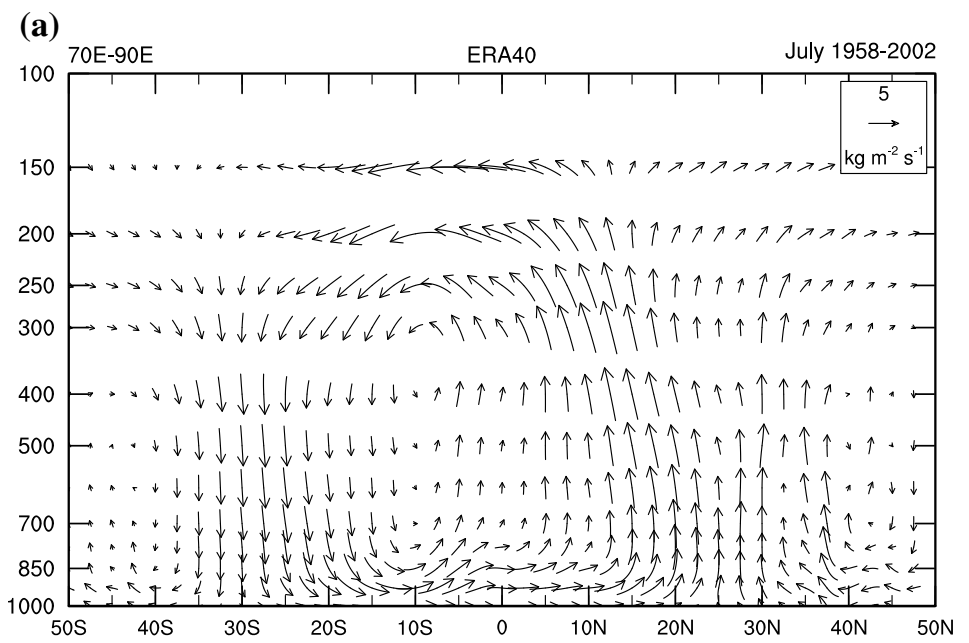

(b)
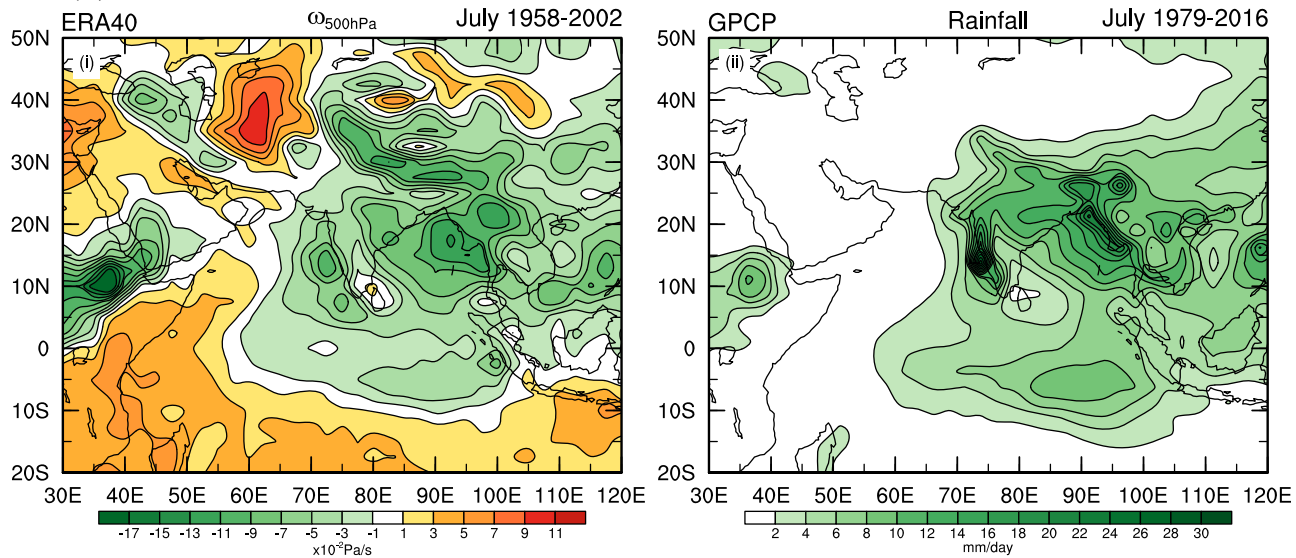

Figure 9. (a) The mean July vertical-meridional circulation, averaged over the Indian longitudes of $70^{\circ}-90^{\circ} \mathrm{E}$ from ERA-40; (b) (i) mean July vertical velocity (in pressure coordinates) at $500 \mathrm{hPa}$ from ERA-40 and (ii) mean July rainfall from GPCP.
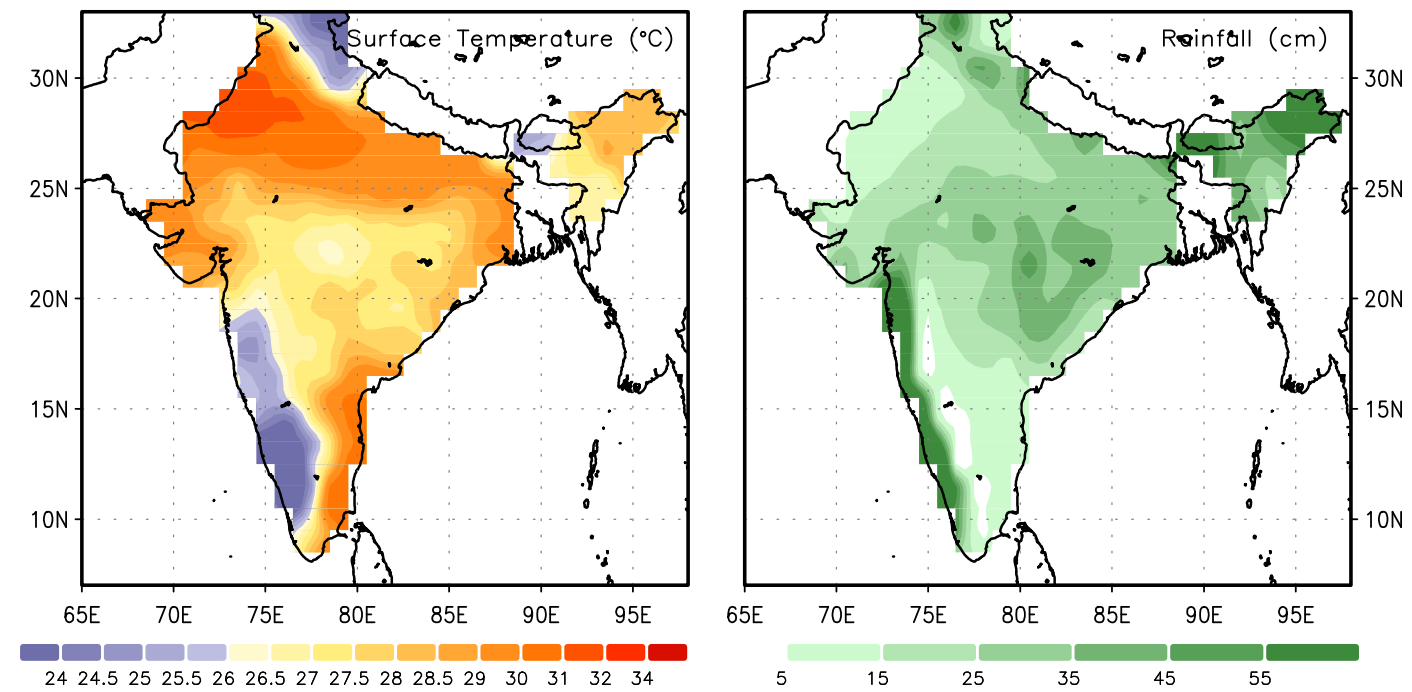

Figure 10. Mean July temperature of the air $\left({ }^{\circ} \mathrm{C}\right)$ at the surface of the Indian region (based on IMD data, Srivastava et al. 2008) and mean July rainfall (in cm) based on IMD grid data (Rajeevan et al. 2006). 
rainfall, and decreases southeastward across the zone.

\section{Is the Indian summer monsoon a large scale land-sea breeze?}

Halley (1686) first suggested that the primary cause of the annual cycle of the monsoon circulation was the differential heating between land and ocean caused by the seasonal march of the Sun. Differential heating, according to Halley, would cause pressure differences in the atmosphere and winds blowing from the high pressure to the low pressure. Halley thus considered the summer monsoon to be a gigantic land-sea breeze in which the ascent of air (and hence clouds and rainfall) over the heated land is generated by the land-ocean temperature contrast. The response of a non-rotating fluid to differential heating at the bottom (with a part of the bottom boundary maintained at a higher temperature than the rest) is shown in figure 11 for two different Rayleigh numbers (i.e., different ratios of viscosity and the forcing temperature gradient). It is seen that the circulation is indeed as suggested by Halley with ascent over the heated region. Halley's theory was modified by Hadley (1735) to incorporate the impact of the Coriolis force, which is important for the spatial scales of thousands of kilometers characterizing the monsoon circulation on the rotating earth. Meehl (1992) pointed out the role of topographic features such as the Tibetan plateau in enhancing the impact of differential heating. The sea-breeze paradigm has been extended to include the effects of elevated diabatic heating from moist convection (e.g., Webster et al. 1998) and the Tibetan plateau (e.g., Li and Yanai 1996). It is seen in figure 11 that the strength of the ascent increases with increasing differential heating. Hence, if indeed, the monsoon circulation/rainfall is driven primarily by the differential heating between land and ocean, it is expected that the ascent/rainfall over land will increase with increasing land-ocean contrast.

Even today, the differential heating between land and ocean is considered to be the primary driver of the monsoon in many papers and most textbooks (e.g., Lau and Li 1984; Webster 1987a; James 1994; Meehl 1992). It has been shown that with enhancement of concentrations of greenhouse gases, the surface temperature rises everywhere, but with more warming over the land than the ocean (Lau and Kim 2017). Assuming that landocean contrast is one of the main drivers of the monsoon rainfall, in the 5th Assessment Report of the Inter-governmental Panel on Climate Change (IPCC Climate Change 2013), the likely enhancement of monsoon rainfall has been attributed to increased land-sea contrast, and more abundant precipitable water in a warmer climate. In a recent study, Jin and Wang (2017) have shown that the summer monsoon rainfall over northern central India has increased since 2002 and suggested that 'this apparent revival of summer monsoon precipitation is closely associated with a favourable land-ocean temperature gradient, driven by a strong warming signature over the Indian subcontinent and slower rates of warming over the Indian Ocean'.

However, observations of the space-time variations of the monsoon over the Indian region are not consistent with the expectation that the ascent/rainfall over land will increase with increasing land-ocean contrast. This was first pointed out by Simpson (1921). In his words, "I believe very few educated people would have any difficulties in giving an answer to the question, what is the cause of the monsoon? They would refer to the high temperature over the land compared with that over the surrounding seas; would speak of ascending currents of air causing an in-draft of sea-air towards the interior of the country. It is only when one points out that India is much hotter in May before the monsoon sets in than in July, when it is at its height - or draws attention to the fact that the hottest part of India - the northwest gets no rain at all during the monsoon (as seen in figure 10 for July) or shows by statistics that the average temperature is much higher in years of bad rains than in years of good rains, that they begin to doubt whether they know the real cause of the monsoon." Such statistics was generated by Kothawale and Rupa Kumar (2002) who showed that the land surface temperature anomaly is positive for droughts and negative for excess monsoon seasons. These observations over land suggest that a stronger monsoon will be associated with a stronger land-ocean gradient, only if for a stronger monsoon, the anomaly of the ocean surface temperatures is also negative and larger in magnitude than that of the land surface temperature.

For June-September, the mean temperature near the land surface (at screen height) from the data at IMD and the mean sea surface temperature 
(a)

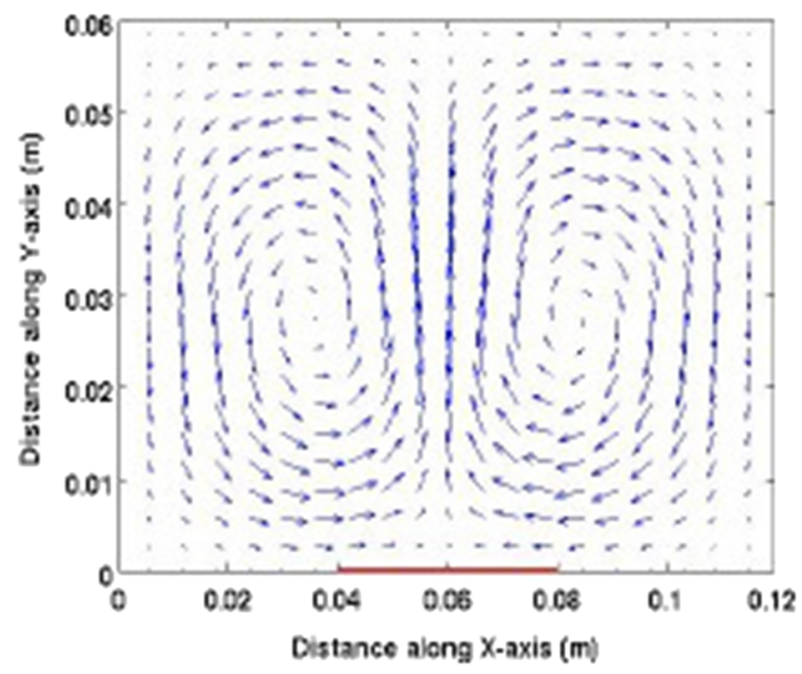

(c)

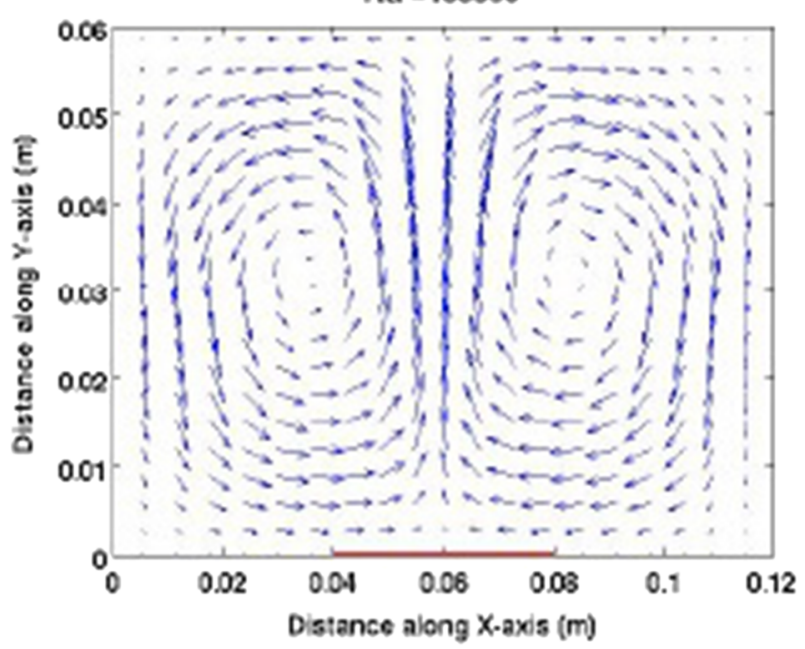

(b)

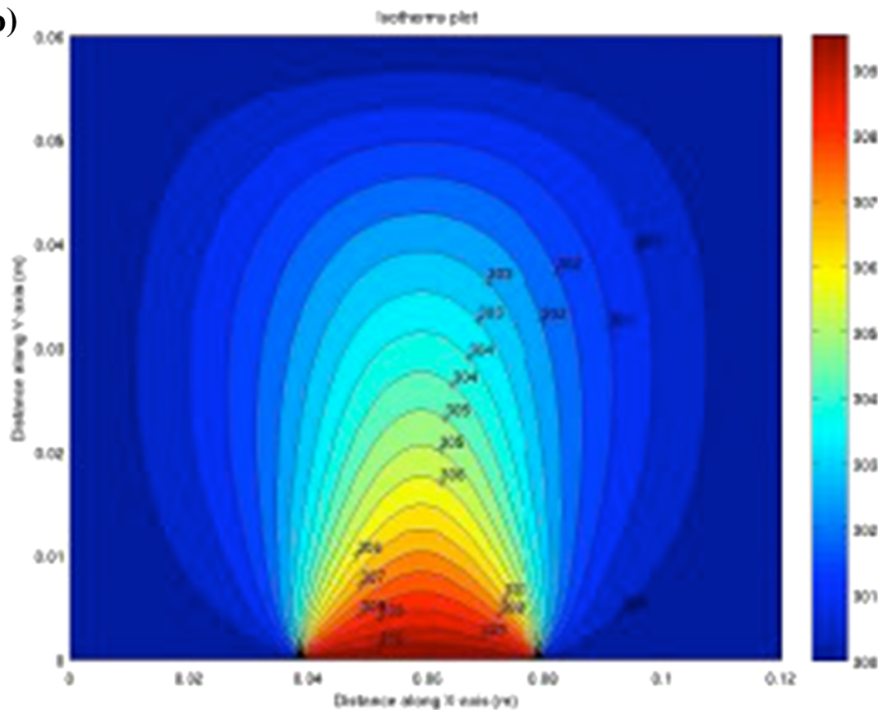

(d)

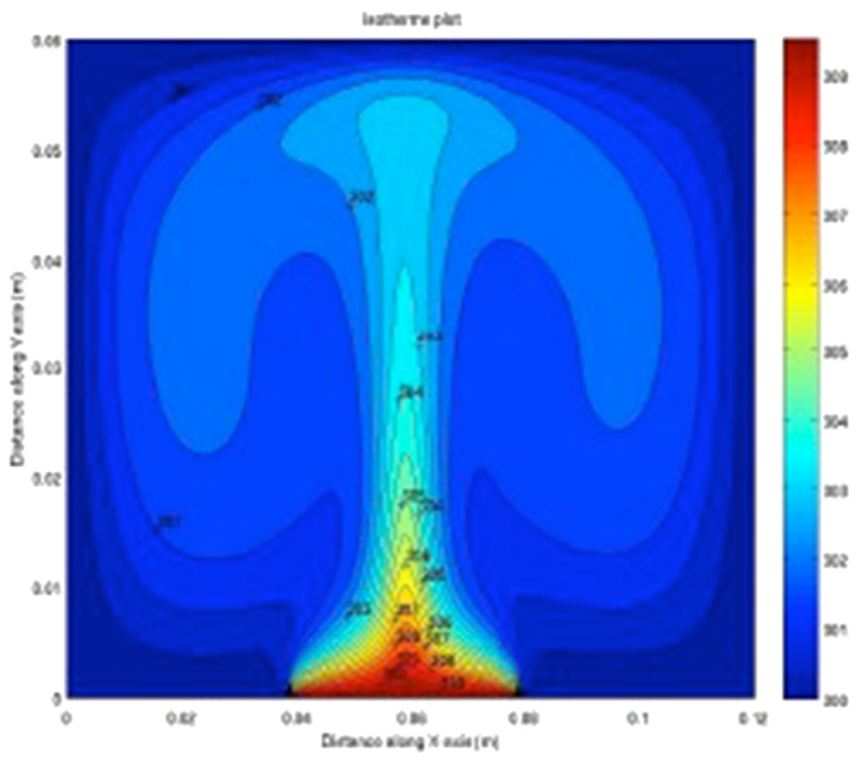

Figure 11. Streamlines and isotherms of a nonrotating fluid heated from below with a part of the lower boundary being hotter (indicated by the red line) than the rest for Rayleigh numbers, $\mathrm{Ra}=10,000$ (top) and $\mathrm{Ra}=100,000$ (bottom) (Srinivasan 2011).

(SST) are shown in figure 12. The mean JuneSeptember air temperature at about $5 \mathrm{~m}$ above the surface (i.e., at sigma 995 level), from NCEP reanalysis data (Kalnay et al. 1996) is also shown in figure 12. Observations over the Bay of Bengal during the Bay of Bengal Monsoon Experiment (BOBMEX, Bhat et al. 2001) in the summer monsoon of 1999, showed that the air temperature just above the sea surface is within 1 degree of the SST (Bhat 2002). It is seen that, as expected, the temperature at the surface as well as at $5 \mathrm{~m}$, over a large fraction of the Indian landmass north of about $20^{\circ} \mathrm{N}$, is higher than that of the oceans. In order to test the hypothesis of the monsoon being a land-sea breeze driven by land-ocean temperature contrast, it is necessary to assess whether an increase/decrease in the monsoon rainfall is associated with an increase/decrease in the temperature gradient between the land surface and the seas/ocean surrounding the subcontinent. For determining whether this is the case, the relationships between the variation of ISMR and (i) the average June-September air temperature at $5 \mathrm{~m}$ over the heated Indian region, (ii) the average June-September air temperature over the surrounding ocean, and (iii) the difference between the land and ocean temperatures, for the period 1950-2014, are investigated. The land regions over 


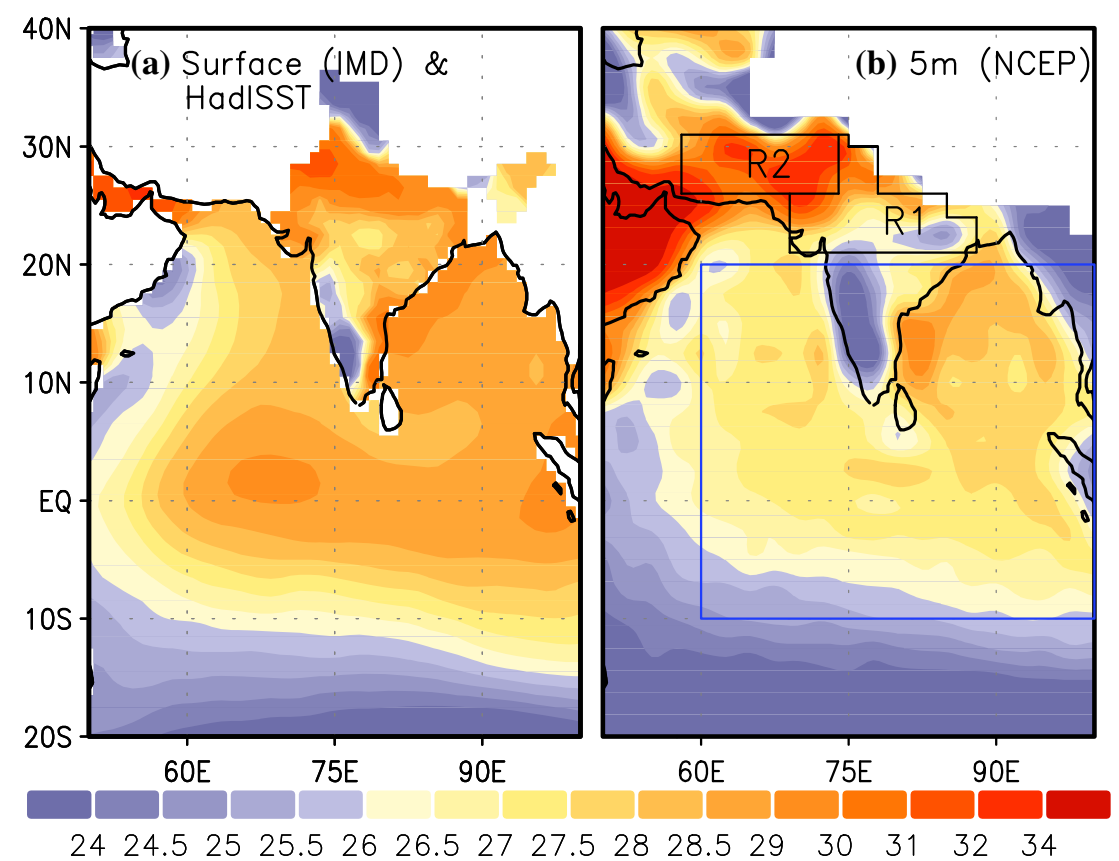

Figure 12. The mean June-September (a) surface air temperature above the Indian region from IMD data (Srivastava et al. 2008) and HadSST over the surrounding ocean and (b) NCEP 5 m temperature.

which the air temperature is averaged are indicated in figure 12 which include the region $\mathrm{R} 1$ over which it rains, the region $\mathrm{R} 2$ which is almost arid as well as the entire heated region $\mathrm{R} 1+\mathrm{R} 2$ and the average air temperature over these regions is denoted by ALS1, ALS2 and ALS, respectively. The oceanic region over which the air temperature is averaged is also shown in figure 12 and the average air temperature over it is denoted by AOS.

The variation of ISMR with ALS, with AOS and with the difference between ALS and AOS, for the period 1950-2014, are shown in figure 13(a). ISMR is significantly negatively correlated (correlation coefficient $=-0.38$ ) with the temperature over the land surface, ALS. When the ALS is $>29.7^{\circ} \mathrm{C}$, ISMR is below normal for almost all the seasons; and when this temperature is $<28.7^{\circ} \mathrm{C}$, ISMR is above normal for almost all the seasons. Similarly, almost all the seasons with high ISMR are characterized with low ALS and low ISMR with high ALS. This is consistent with the results of the study of Kothawale and Rupa Kumar (2002) and suggests that rather than the land surface temperature determining the rainfall, it is itself determined by the rainfall (or lack thereof). In fact, the temperature of the air over the oceanic region is also negatively correlated with ISMR, but the scatter is seen to be large and the relationship is rather weak with the correlation coefficient of -0.18 . The overall relationship of ISMR with the difference in ALS-AOS, is similar to but weaker than that of ISMR with the ALS and the correlation coefficient between the two is smaller, i.e., -0.23 . The variation of ISMR with ALS-AOS is rather interesting. When the land-ocean contrast is large, there is a very large scatter. However, when it is small (i.e., ALS-OLS $<0.35^{\circ} \mathrm{C}$ ), all but one season are characterized with above-normal ISMR. Thus, smaller land-ocean contrast is almost always associated with above (and not below!) average ISMR.

We next examine whether the land-sea breeze concept holds for at least the maximally heated region without much rain, i.e., $\mathrm{R} 2$. It is seen from the variation of ISMR with ALS2 and with the difference ALS2-AOS depicted in figure 13(b), that ISMR is poorly correlated with ALS2 as well as the contrast of that with AOS. The only significant relationship is between ALS1 and ISMR (figure 13b), which is similar to that between the temperature at the surface of the entire region, ALS, and ISMR with higher ISMR associated with lower ALS1 and lower ISMR with higher ALS1, in general.

To summarize, an increase in the monsoon rainfall is generally associated with a decrease in the temperature above the land surface. This suggests that rather than the land surface temperature determining the rainfall, it is itself determined 
(a)
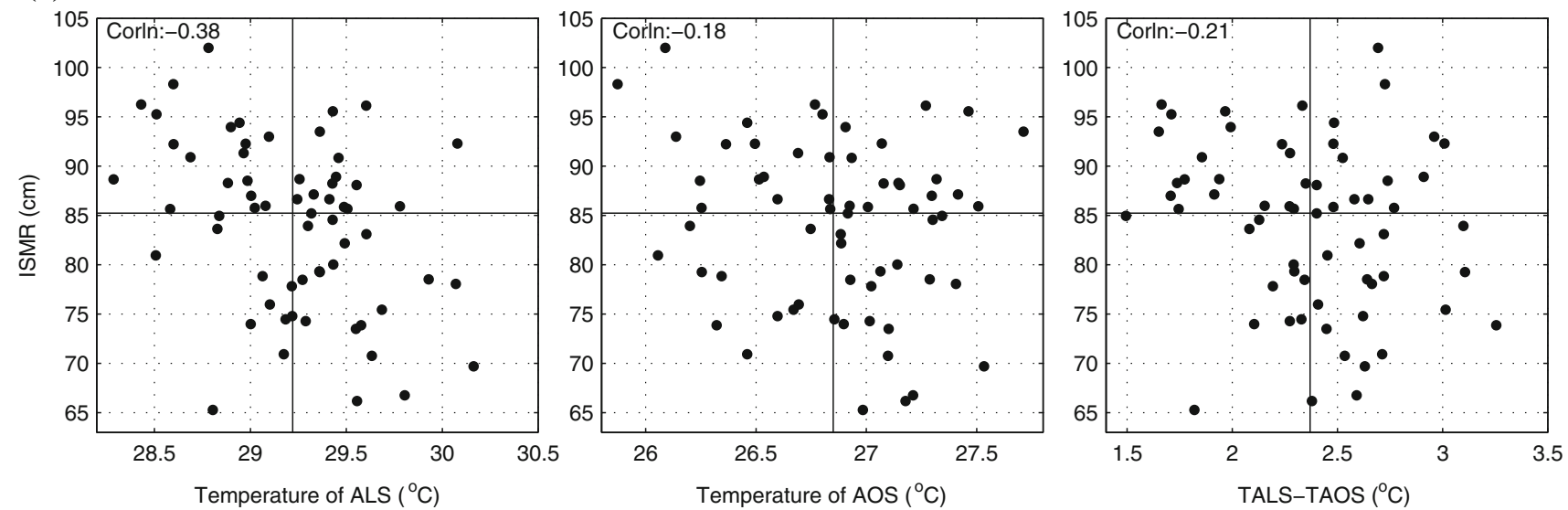

(b)
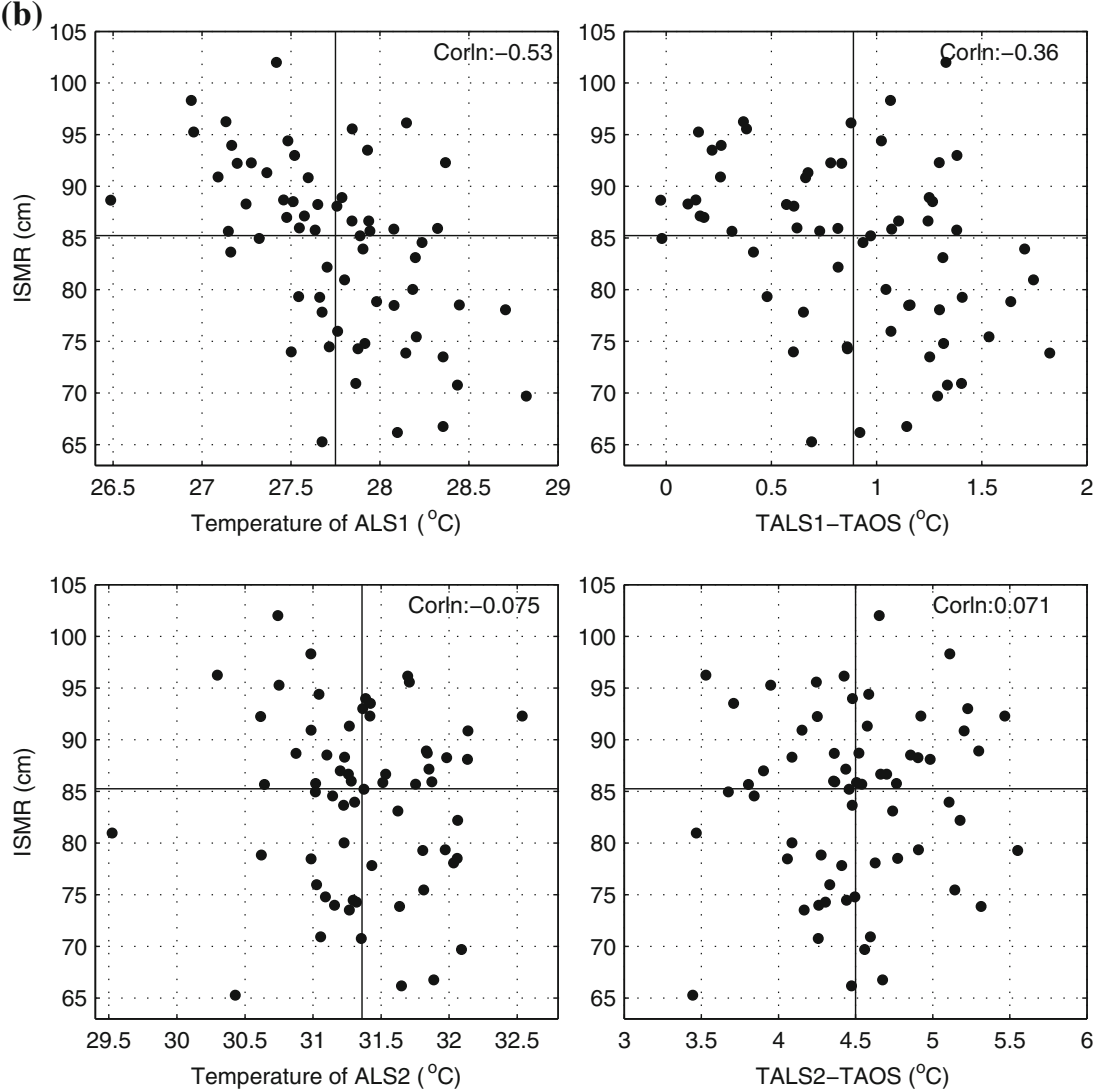

Figure 13. (a) Variation of ISMR with NCEP $5 \mathrm{~m}$ temperature for (i) ALS, average over the land region R1 + R2 shown in figure 12. (ii) AOS average over the oceanic region. (iii) ALS-AOS; correlation coefficients are also indicated in each case. (b) Variation of ISMR with ALS1 (average temperature over R1 in figure 12) and ALS1-AOS (top) and ALS2 (average temperature over R2 in figure 12) and ALS2-AOS (bottom).

by the rainfall (or lack thereof). Furthermore, an increase in the monsoon rainfall is also generally not associated with an increase in the land-ocean temperature contrast as expected from the landsea breeze model, but a decrease in the land-ocean temperature contrast, although the relationship is weak.
Walker et al.'s (2015) study of the interannual variation of an index for the South Asian Summer Monsoon (SASM), defined as the vertically integrated moisture flux convergence over a representative region, i.e., $60^{\circ}-100^{\circ} \mathrm{E}, 10^{\circ}-30^{\circ} \mathrm{N}$, has shown that the correlation of the SASM index with the temperature at $850 \mathrm{hPa}$ over the land 
is negative and over the surrounding ocean is positive. Thus, the land-ocean temperature gradient at $850 \mathrm{hPa}$ decreases with the SASM index, and stronger SASM is associated with a decreased $850 \mathrm{hPa}$ land-ocean thermal contrast. This result for $850 \mathrm{hPa}$ is similar to our finding of the association of stronger Indian monsoon with weaker land-ocean contrast at $5 \mathrm{~m}$.

Thus, observations of the interannual variation of the monsoon are not consistent with the land-sea breeze hypothesis for the monsoon. Yet, Simpson's (1921) criticism of the land-sea breeze model was ignored by almost everyone who has written on the subject subsequently.

\section{Alternative hypothesis}

Several decades before Simpson, Blandford (1886) had opposed the idea of land-ocean contrast as being considered the prime cause of the monsoon. He suggested that heating of the atmosphere above the heated land can lead to only feeble convergence in spring and cannot explain the heavy rainfall associated with the summer monsoon. In his words, "During these spring months, on the Bay of Bengal and the Arabian Sea, the winds are light, frequently alternating with calms and somewhat variable; .... The change that ensues at the end of May or in June, when the surrounding seas are swept by a strong monsoon current, and heavy and continued rain sets in on the coasts of India, is very marked, and has long been recognized in popular language as 'the burst of the monsoon'. The essential cause of the change appears to be that during the spring months, the sea-winds which feed the storms of that season are the relatively damp but by no means saturated air of the surrounding seas; or if saturated, at least not so to any considerable vertical height above the sea surface. But in more southerly latitudes, in the neighbourhood of the equator, is a belt of the atmosphere, into which the southeast trades of the South Indian Ocean pour a steady supply of almost saturated air. At all times of the year, more or less convection goes on in this belt, as proved by its raininess in all the seasons; and consequently, it affords a great reservoir of air, which, up to an indefinite height above the sea surface, borders at all times on a state of saturation. Now it appears to be the eventual rush of this air towards the region of low pressure, developed over India gradually during the spring months, that constitutes the burst of the monsoon. Once started, the energy of its movement is sustained by the condensation of its own copious vapour; by the latent heat so set free. The energy of convection furnished by the heated atmosphere of the plains, is competent only to keep up the feebler indraught that obtains during the spring months; and indeed even this indraught is maintained partly by the moderate condensation of cumulus and local thunderstorms, fed by the vapour it brings.

The solar heat, directly absorbed by the dry land atmosphere or taken up from the heated ground, bears much the same relation to the general air movement, as the pull on the trigger does to the propulsion of the rifle ball. It determines the disturbance of atmospheric equilibrium but it does not furnish the energy of the resulting air stream. That energy is supplied in the latent heat of the indrawn vapour. So long as this supply is small and limited to the shallow stratum of air immediately fed by the evaporating surface beneath it, so long is the air movement feeble and interrupted. And it is only when the barometric gradient from south to north has become sufficiently great to tap the great reservoir of latent energy, supplied by the evaporation of the southeast trade zone, that the air current becomes strong and sustained, constituting the summer monsoon; sustained, too, long after the heated land surface has been in a great measure quenched and cooled by the rainfall."

We can now identify the system described by Blandford (1886) to which he attributed the monsoon rainfall, as the equatorial trough (Riehl 1954, 1979) or the ITCZ (Charney 1969), which is the system responsible for the large-scale rainfall over tropical oceans. The ITCZ is the ascending limb of the thermally direct overturning tropical circulation, the Hadley cell, which shapes meridional temperature gradients and approaches conservation of angular momentum in its upper branch. The idealized Hadley cell is the zonally averaged circulation in the meridional-vertical plane, driven by maximum heating at the equator (figure 14) and is rather similar to the circulation of a non-rotating fluid driven by differential heating (Benard convection) at the surface, with high Rayleigh number (figure 11).

In response to the seasonal variation in the incident solar radiation which leads to a seasonal variation in the latitude of maximum heating, the location of the ITCZ varies with season. The seasonal variation of the Sun's zenithal position and of the latitude of the zonally averaged equatorial trough is shown in figure 15(a). It is seen that 


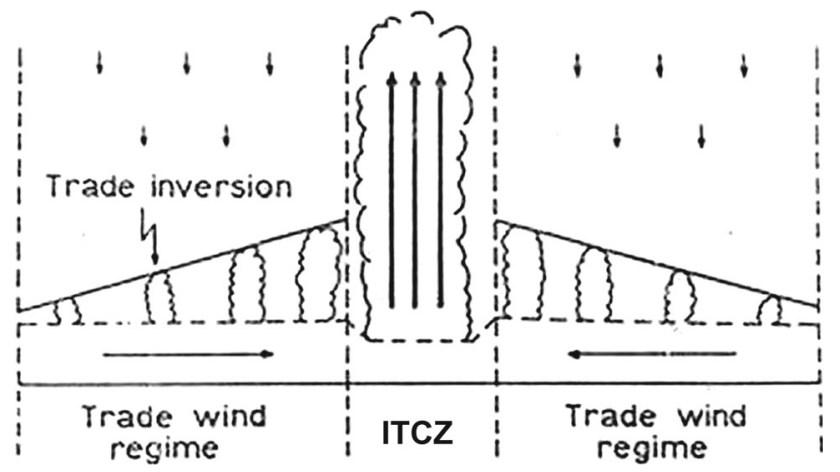

Figure 14. Schematic picture of the Hadley cell.

(a)

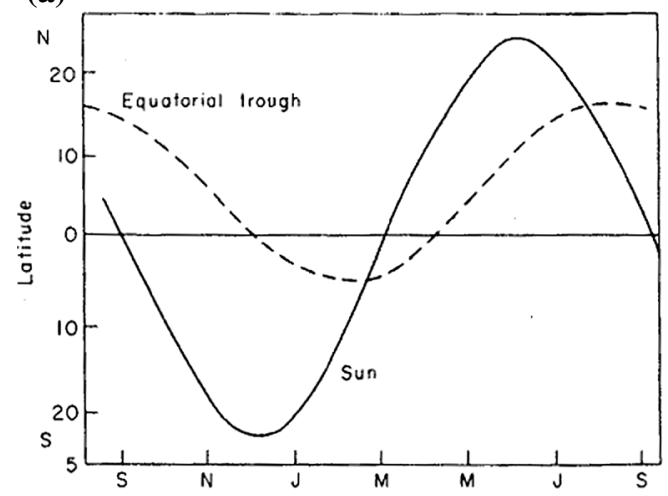

(b)
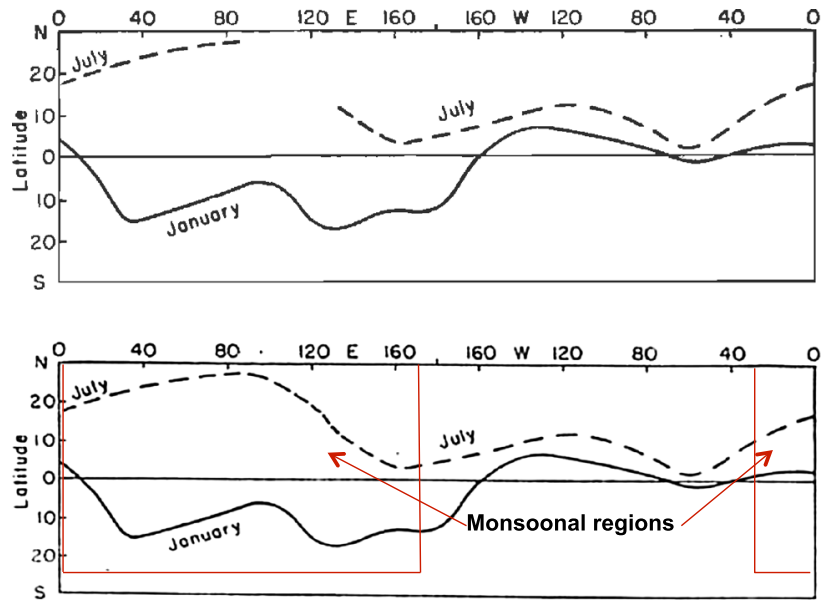

Figure 15. (a) Variation of the monthly mean Sun's zenithal position and of the latitude of the zonally averaged equatorial trough (adapted from Riehl 1979). (b) Mean positions of the equatorial trough in January and July after Riehl (1954, above) and Riehl (1979, below). Boundary of the monsoonal regions is shown in red.

the zonally averaged equatorial trough follows the Sun with a lag of about 2 months and the amplitude of its seasonal variation is smaller than that of the Sun, particularly in the southern summer. According to the alternative hypothesis, the monsoon is a manifestation of the seasonal variation of the rising limb of the Hadley cell, i.e., the equatorial trough/ITCZ or near equatorial trough
(Ramage 1971) associated with the occurrence of this system over the monsoonal region in the summer. I believe that Charney perceived the monsoon as a manifestation of the seasonal variation of the ITCZ, while Riehl became convinced, sometime between 1954 and 1979, that the basic system over the Asian monsoonal region was the equatorial trough (figure 15b). Thus, it is suggested that the system associated with monsoon rainfall is the same as that associated with the organized rainfall over the warm tropical oceans and not a system special to monsoonal regions as suggested in the land-sea breeze model. Note that the amplitude of the seasonal migration is indeed larger over the monsoonal regions delineated by Ramage (1971).

However, there have been serious objections to attributing the monsoon to seasonal migration of the ITCZ. Noting the large latitudinal extent of the region characterized by low values of OLR in July over $70^{\circ}-90^{\circ} \mathrm{E}$ (figure 16), Murakami (1987) pointed out "Over the Indian Ocean, a persistent, belt-shaped distribution of low values of infrared radiation can be seen mainly during the winter (December to February) season along the area connecting northern Madagascar and Sumatra. The lack of a similar distribution during the summer (June to August) season indicates that the ITCZ over the Indian Ocean changes its existence drastically from winter to summer." In the depiction by Webster (1987b) of the monsoonal regions over the tropical OLR patterns and streamlines, they are shown as distinct from those associated with the canonical ITCZ. Thus, it is important to test the validity of this hypothesis.

\section{Divergent tropical circulations: heat lows and the ITCZ}

We note that the response of the tropical atmosphere to heating from the surface is either a heat low characterized by shallow circulation with ascent over the region of maximum heating/ temperature restricted to within the first 2-3 $\mathrm{km}$ from the heated surface, or an ITCZ with ascent of moist air throughout the troposphere and deep convection. Trenberth et al.'s (2000) analysis has brought out clearly the different patterns of overturning associated with the surface trough in the tropics. They show that there are two patterns of special interest that have vertical structures that remain largely unchanged throughout 

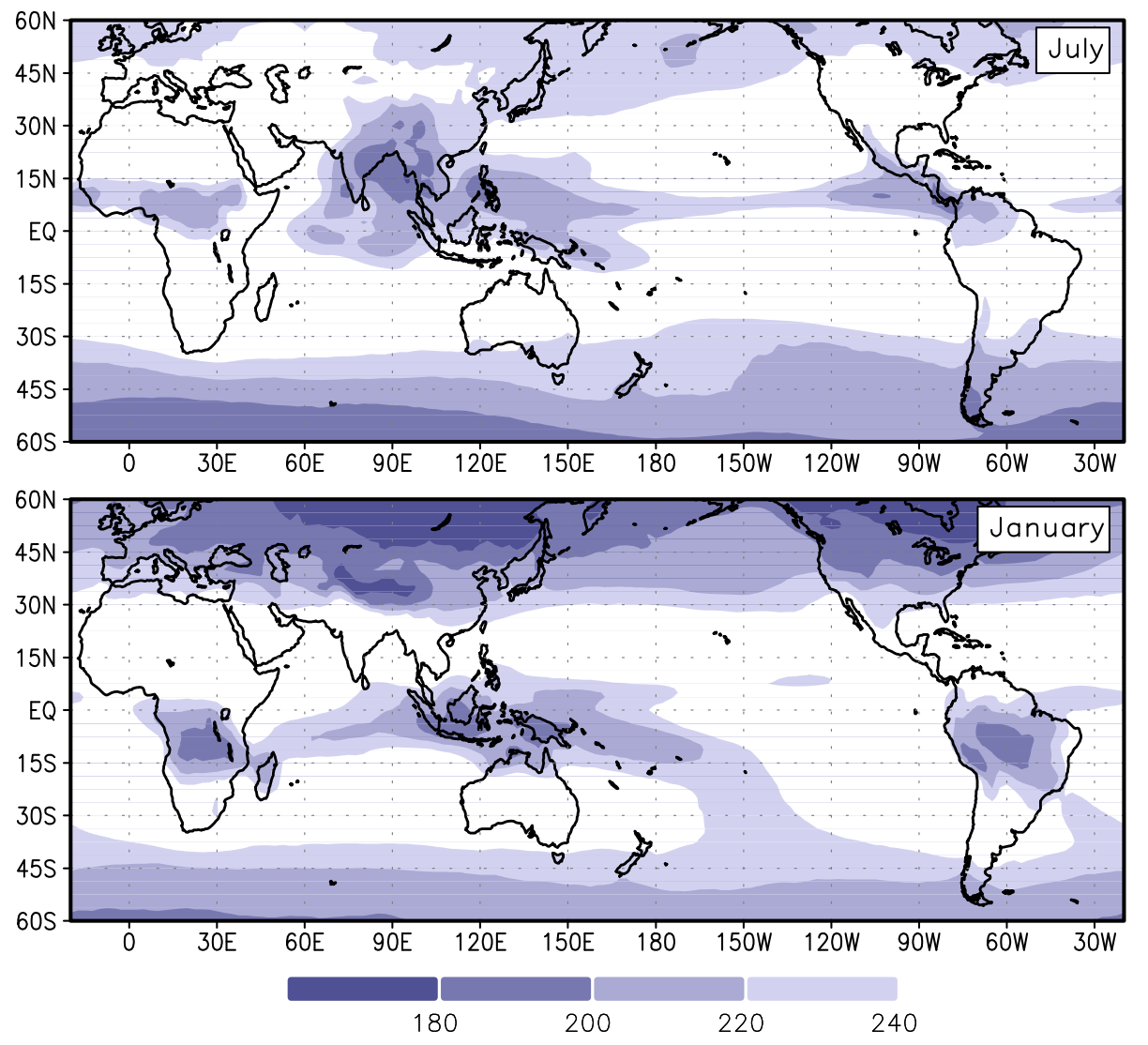

Figure 16. Mean OLR (W/ $\left.\mathrm{m}^{2}\right)$ for January (bottom) and July (top). NCEP CEOF $1 \mathrm{~V}$. Struc., $\mathrm{kg} \mathrm{m} \mathrm{m}^{-1} \mathrm{~s}^{-1}$ NCEP CEOF $2 \mathrm{~V}$. Struc., $\mathrm{kg} \mathrm{m}^{-1} \mathrm{~s}^{-1}$

(a)

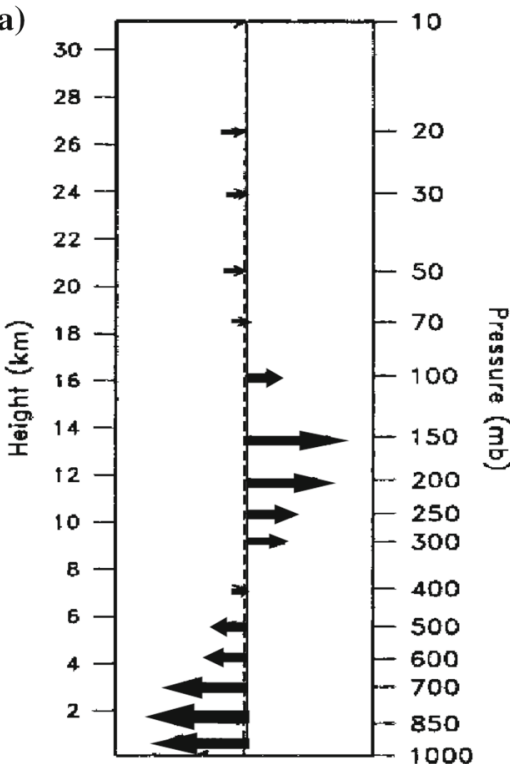

(b)

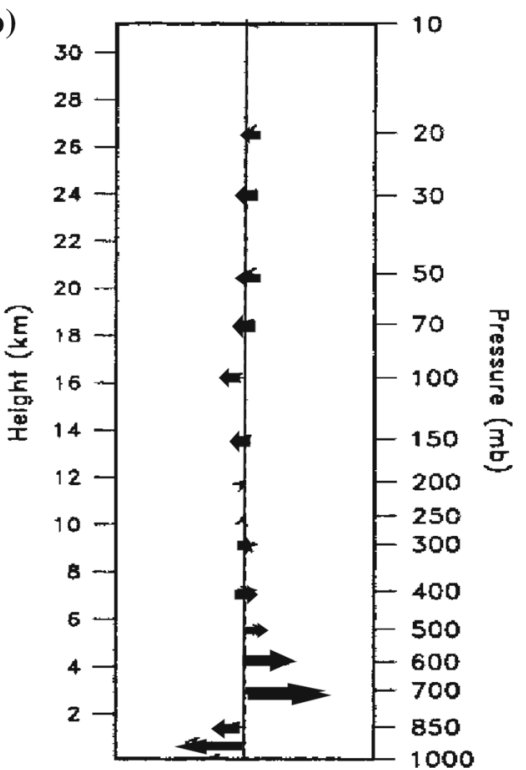

Figure 17. Vertical structure functions of the mass weighted divergent velocity field from the complex EOF analysis for (a) CEOF1 and (b) CEOF2, from NCEP reanalysis seasonal mean fields for 1979-1993. The vectors are referenced to that at $1000 \mathrm{mb}$, which is directed along the $x$ axis; the scale factor is given below; and the units are $\mathrm{kgm}^{-1} \mathrm{~s}^{-1}$ (after Trenberth et al. 2000).

the year. The first, CEOF1 (dominant empirical orthogonal function), involves convergence up to the mid-troposphere and divergence aloft (figure 17a). This mode accounts for $60 \%$ of the annual cycle variance. The vertical motion patterns and precipitation in the tropics and subtropics (both wet and dry areas) are largely accounted for by this dominant mode. The second 
mode corresponds to a shallow lower tropospheric overturning cell (figure 17b), which accounts for $20 \%$ of the mean annual cycle of the divergent wind. Trenberth et al. (2000) also showed that there is a close correspondence between the vertical velocity at $500 \mathrm{hPa}$ and the vertical velocity at $400 \mathrm{hPa}$ corresponding to the dominant mode. Thus, while the first mode is associated with the ITCZ, the second is associated with a heat low type circulation.

Ramage (1971) pointed out that 'Heat lows are a fine-weather phenomenon, conversely nearequatorial troughs are associated with unsettled weather. However, in a climatological sense, in the summer hemisphere, they (i.e., the two modes identified by Trenberth et al. 2000) together comprise a continuous low-pressure belt.' According to the hypothesis considered here, the seasonal variation of the rainfall is associated with the seasonal migration of the ITCZ. It is seen from figure 8 (a and b) that the low at the surface in the northwestern part of the monsoon zone extends to $850 \mathrm{hPa}$, but not to the $700 \mathrm{hPa}$ level, indicating that it is a heat low. On the other hand, the trough over the eastern part of the monsoon zone, which extends to $700 \mathrm{hPa}$ level and beyond is part of a deeper convergence zone.

\section{The basic system responsible for the Indian summer monsoon: the ITCZ}

The seasonal variation in the direction of the surface winds, which is the basis for the traditional definition of the monsoon, is associated with the seasonal variation of the surface trough. According to the hypothesis considered here, the seasonal variation in the rainfall over the Indian region is associated with the occurrence of the ITCZ. So, it is important to determine whether the largescale monsoon rainfall of the Indian summer is indeed associated with a system which has all the important characteristics of the ITCZ. The important attributes of the ITCZ are considered to be: intense convergence in the boundary layer which is associated with cyclonic vorticity above the boundary layer, ascent of moist air throughout the troposphere and deep convection and heavy precipitation (Charney 1969). However, while cyclonic vorticity above the boundary layer (at $850 \mathrm{hPa}$ ) is a necessary condition for organized convection, it is not a sufficient condition. Such convergence can also be associated with a heat low/trough.
Thus, it is important to determine whether the system is also characterized by ascent above the level of the typical heat low cell, i.e., at $700 \mathrm{hPa}$ and above. In fact, during the summer monsoon, over the Indian region, the $700 \mathrm{hPa}$ trough zone is known to be characterized by maximum cyclonic vorticity above the boundary layer, convergence in the lower troposphere (Anjaneyulu 1969) and maximum non-orographic precipitation (Raghavan 1973).

Support for the hypothesis of the basic system responsible for the Indian summer monsoon being the ITCZ, was provided by Sikka and Gadgil's (1980, henceforth SG) study of the daily satellite imagery during April-October 1973-1977. They analyzed the daily variation of the location of the maximum cloudiness zone (MCZ) over the Indian longitudes of $70^{\circ}, 80^{\circ}$ and $90^{\circ} \mathrm{E}$, identified from satellite imagery, as well as the daily variation of the $700 \mathrm{hPa}$ trough over the Indian region. SG showed that the cloud-band over the Indian region on a day during an active spell of the summer monsoon looks very similar to that associated with the ITCZ over the Pacific and that over the equatorial Indian Ocean in the pre-monsoon season. In the hemispheric infrared imagery from INSAT for an active monsoon day, 7 August 2007, as shown in figure 18(a), the MCZ over the Indian region is clearly seen. For the same day, the rainfall over the Indian region and the winds at 850 and $700 \mathrm{hPa}$ over the larger region $30^{\circ}-125^{\circ} \mathrm{E}$ and $25^{\circ} \mathrm{S}-45^{\circ} \mathrm{N}$ are also shown in figure 18. It is clearly seen that the MCZ is associated with high cyclonic vorticity at 850 and $700 \mathrm{hPa}$. Thus, the system on an active monsoon day over the Indian region does possess the most important attributes of the ITCZ.

Some basic features of the monthly and higher frequency variation of the MCZ identified from satellite imagery, were discovered in the SG study. It was shown that during June-September, there are two favourable locations for the MCZ, one north of about $20^{\circ} \mathrm{N}$ and another over the warm waters of the equatorial Indian Ocean. The latitude of the minimum occurrence in low-frequency belt between $7^{\circ}$ and $12^{\circ} \mathrm{N}$, was taken as the dividing latitude between the northern and the southern MCZs. From the monthly variation of the axes of the two MCZs at $80^{\circ}$ and $90^{\circ} \mathrm{E}$ shown figure 19 (a), the northward migration of the MCZ from the equatorial Indian Ocean in May, to the Indian monsoon zone in July is clearly seen. The equatorial MCZ is seen to coexist with the northern MCZ during June-September. 


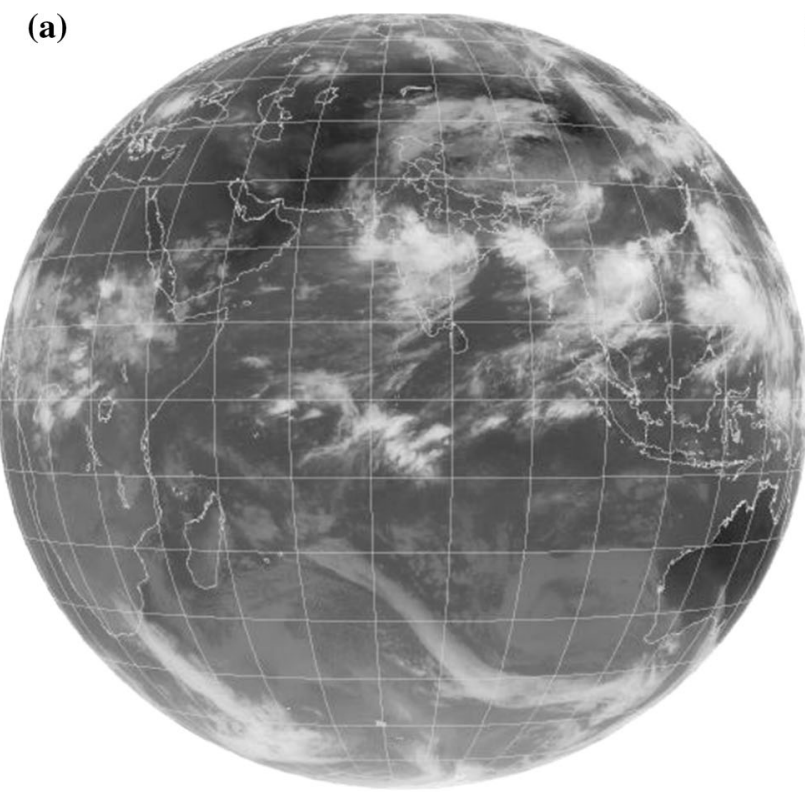

(b)

(c)

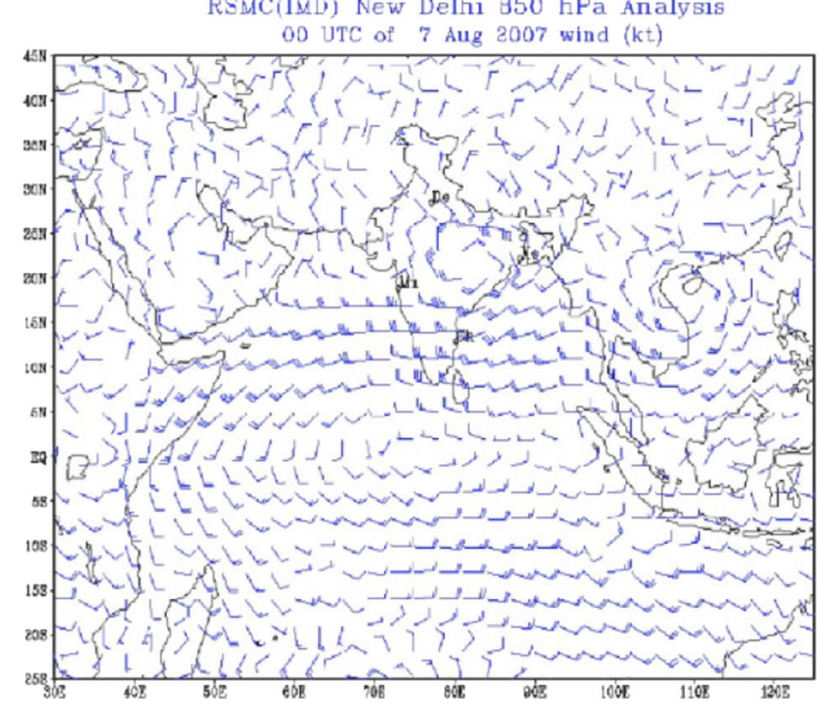

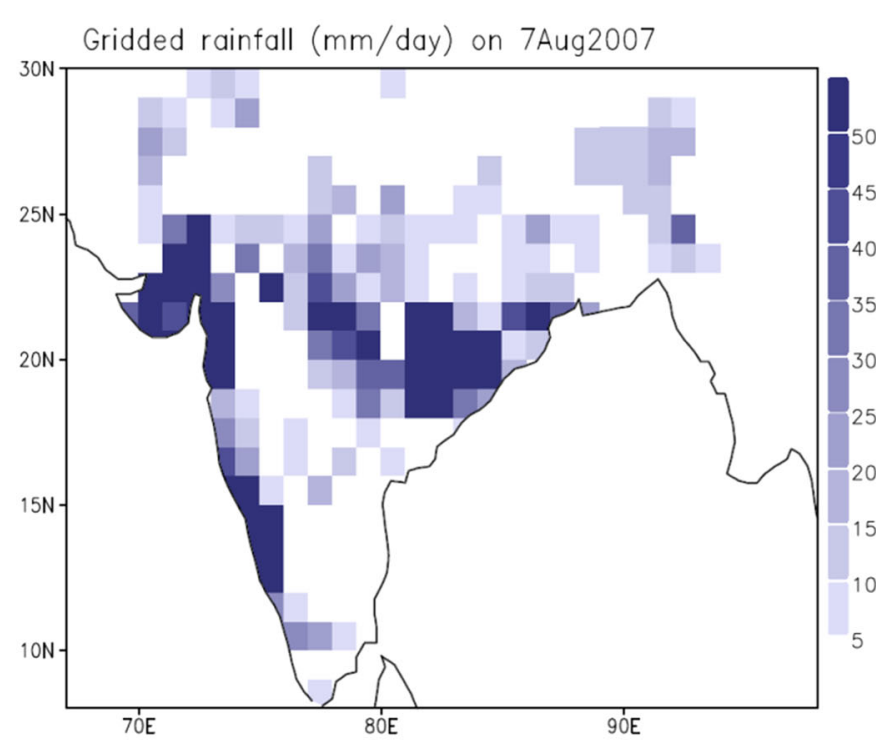

(d)

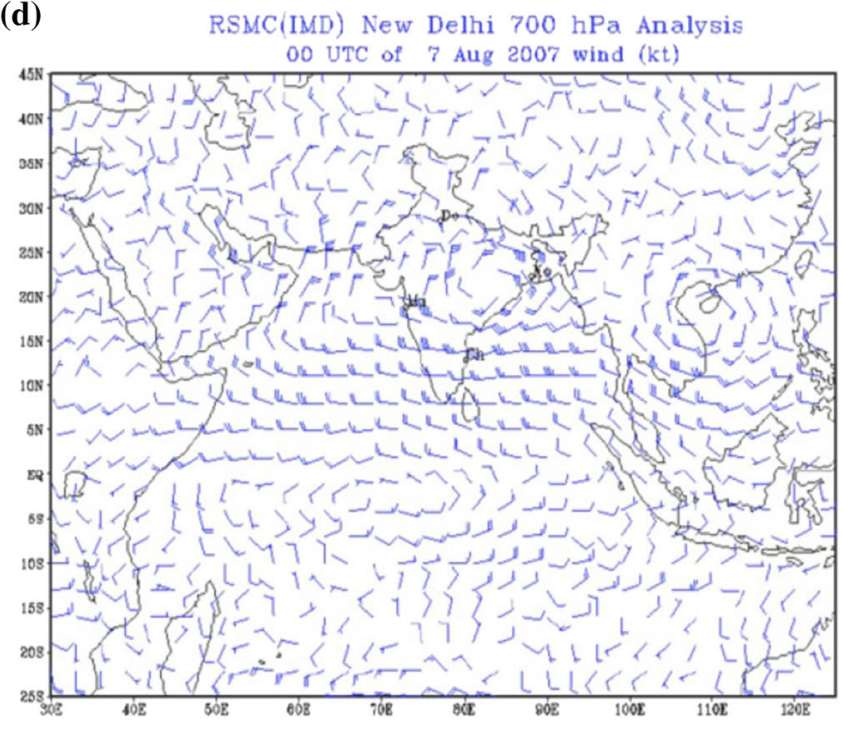

Figure 18. For 7 August, 2007. (a) Infrared satellite image showing MCZ over the Indian region, (b) rainfall, and (c, d) winds at 850 and $700 \mathrm{hPa}$.

The most prominent feature of the daily variation of the MCZ every year was found to be a series of northward propagations of the cloud bands from the equatorial Indian Ocean onto the Indian region (figure 19b). Such propagations are coherent across $70^{\circ}-90^{\circ} \mathrm{E}$ and occur every year, irrespective of whether it is a drought or a good monsoon season. SG showed that there is a high correlation between the axis of the MCZ and the $700 \mathrm{hPa}$ trough on a day-to day basis and that these propagations are also seen in the daily variation of the $700 \mathrm{hPa}$ trough.

Thus the MCZ over the Indian region on an active monsoon day resembles that associated with the ITCZ, it is associated with cyclonic vorticity at 850 and $700 \mathrm{hPa}$, and there is a high correlation between the axis of the MCZ and that of the $700 \mathrm{hPa}$ trough which is known to be associated with intense convergence in the lower troposphere and maximum non-orographic rainfall. Hence, SG concluded: "Putting all this together, it becomes clear that the organized moist convection associated with the monsoon may be attributed to a continental ITCZ over the region. This surmise is consistent with the characteristics of an ITCZ, viz., the presence of a prominent zonally oriented region of moist convection in the tropics associated with high cyclonic relative vorticity and convergence. 


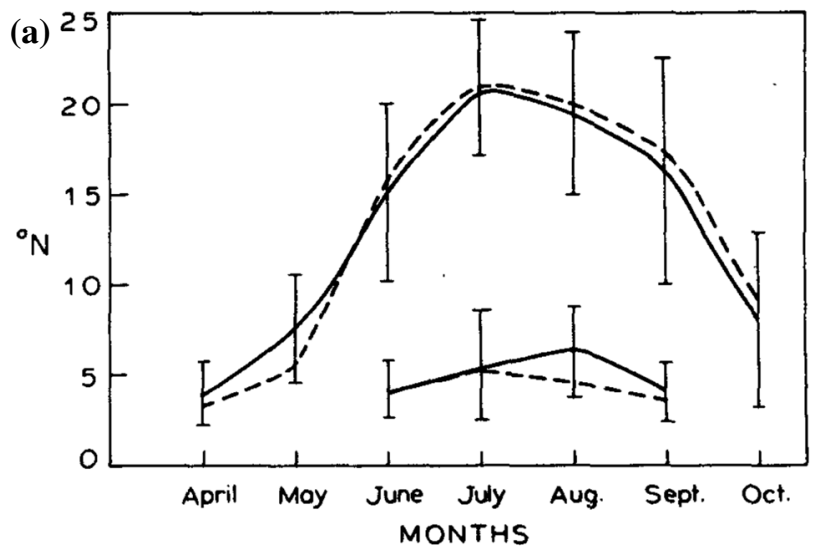

(b)
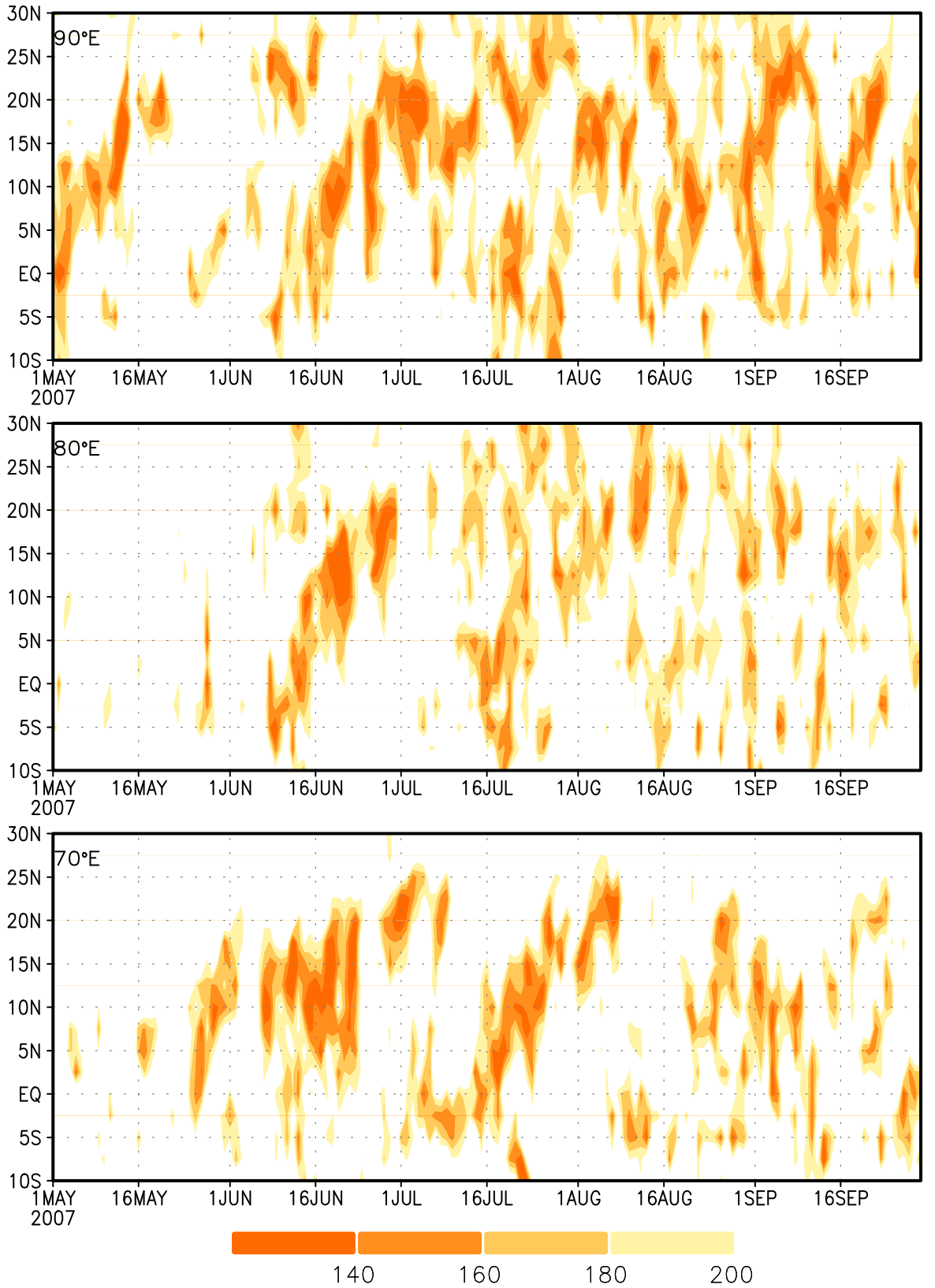

Figure 19. (a) Variation of the monthly mean location of the northern and equatorial $\mathrm{MCZ} ; 90^{\circ} \mathrm{E}$ solid, $80^{\circ} \mathrm{E}$ dashed $($ after Sikka and Gadgil 1980). (b) Daily variation of low OLR zones at $70^{\circ}, 80^{\circ}$ and $90^{\circ} \mathrm{E}$ during the summer monsoon of 2007 . 

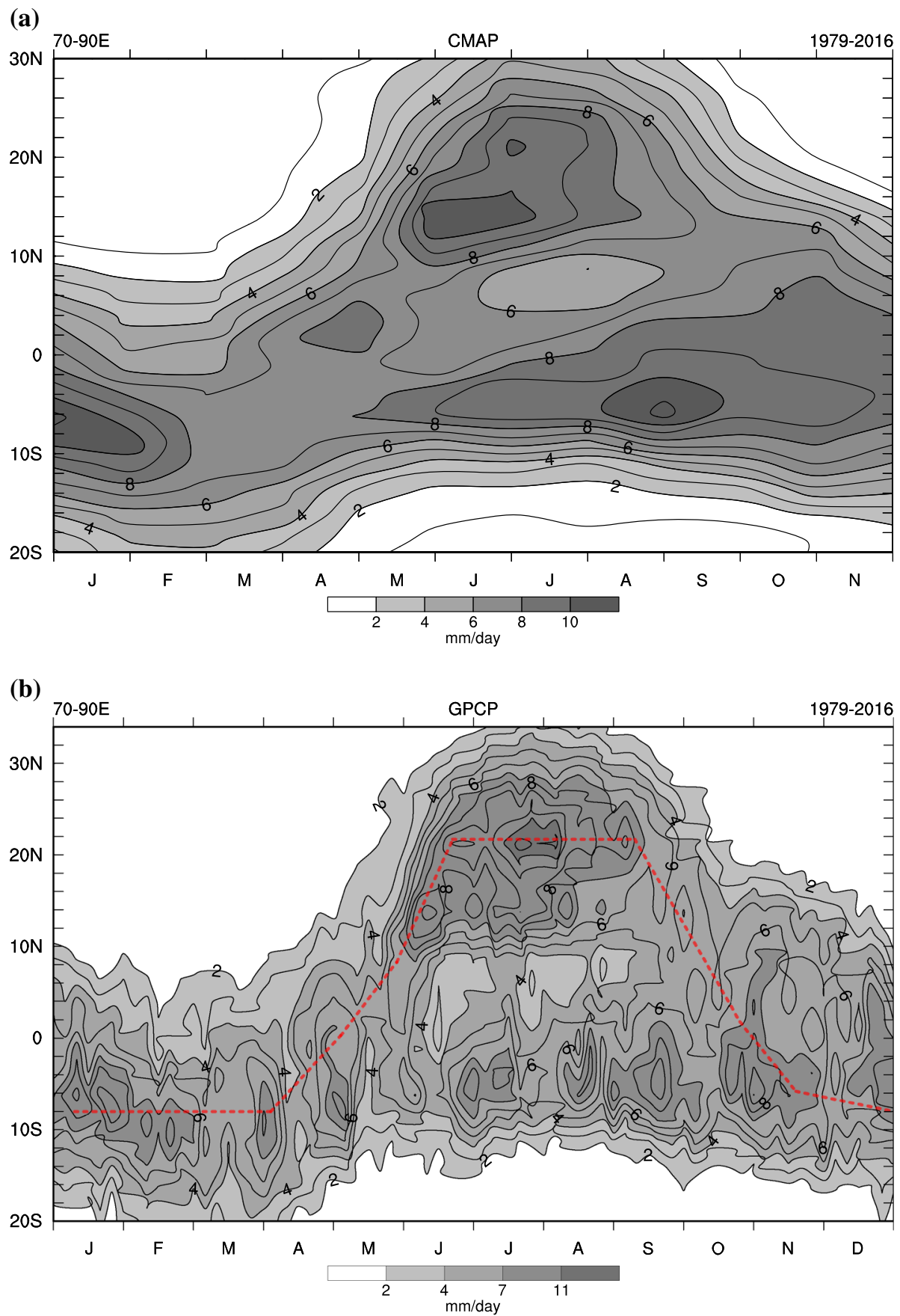

Figure 20. Variation of the (a) mean monthly rainfall ( $\mathrm{mm} /$ day) and (b) mean pentad rainfall (mm/day) averaged over $70^{\circ}-90^{\circ} \mathrm{E}$. (c) Average over the Indian longitudes of $70^{\circ}-90^{\circ} \mathrm{E}$ of the mean vertical circulation for January (top) and July (bottom).

Thus the monsoon MCZ could be considered as a manifestation of a continental ITCZ (CTCZ) and the secondary MCZ of an oceanic one." It is seen from the mean circulation averaged over $70^{\circ}-90^{\circ} \mathrm{E}$, in the meridional-vertical plane for January and July (figure 9a) that the structure of the system is that of the ITCZ or Trenberth et al. (2000)'s first mode.
The variation of the monthly rainfall averaged over $70^{\circ}-90^{\circ} \mathrm{E}$ (figure $20 \mathrm{a}$ ) shows northward migration of the rainbelt from a location over the equatorial Indian Ocean in northern winter to the Indian monsoon zone in the summer. It is also seen that a secondary rainbelt occurs over the equatorial regions in the summer monsoon season. On the scale of pentad, the changes in the location 


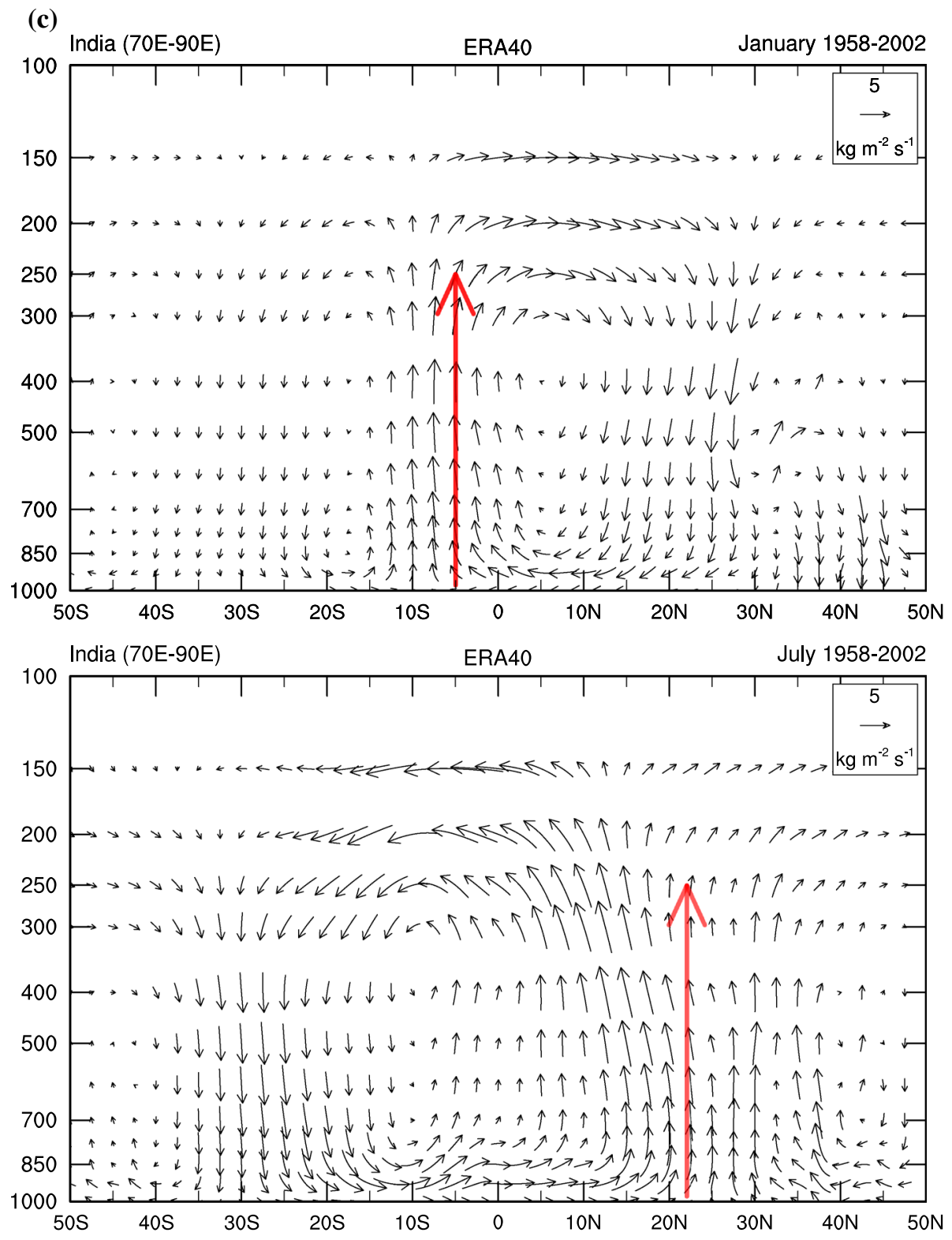

Figure 20. (Continued.)

of the rainbelt are seen to be large and rather abrupt (figure 20b). The vertical circulation averaged over $70^{\circ}-90^{\circ} \mathrm{E}$ (figure 20c) shows that the rainbelt is associated with an ITCZ, characterized by strong ascent throughout the troposphere in the boreal summer as well as the austral summer. The seasonal reversal in the overturning circulation implicit in the definition of the monsoon (Trenberth et al. 2006) is clearly seen for the case of the Indian monsoon in figure 20(c). Thus the Indian summer monsoon can be considered as a manifestation of the seasonal migration of the ITCZ. Walker et al. (2015) have shown that the South Asian summer monsoon rainfall can also be attributed to a large-scale convergence zone by demonstrating a high correlation between the precipitation over the region with the integrated moisture convergence over $60^{\circ}-100^{\circ} \mathrm{E}, 10^{\circ}-0^{\circ} \mathrm{N}$.

If the monsoon is indeed associated with an ITCZ over the Indian region, why does the mean July OLR pattern indicate a low OLR region of much larger latitudinal extent than over the Indian longitudes in the boreal summer than the low OLR regions elsewhere or in the boreal winter as pointed out by Murakami (1987)? This is because of two special features of the intraseasonal variation over the Indian longitudes during the summer monsoon: (i) the presence of two ITCZs (or rather two TCZs since convergence in both cannot be intertropical) - the oceanic as well as the continental one and 

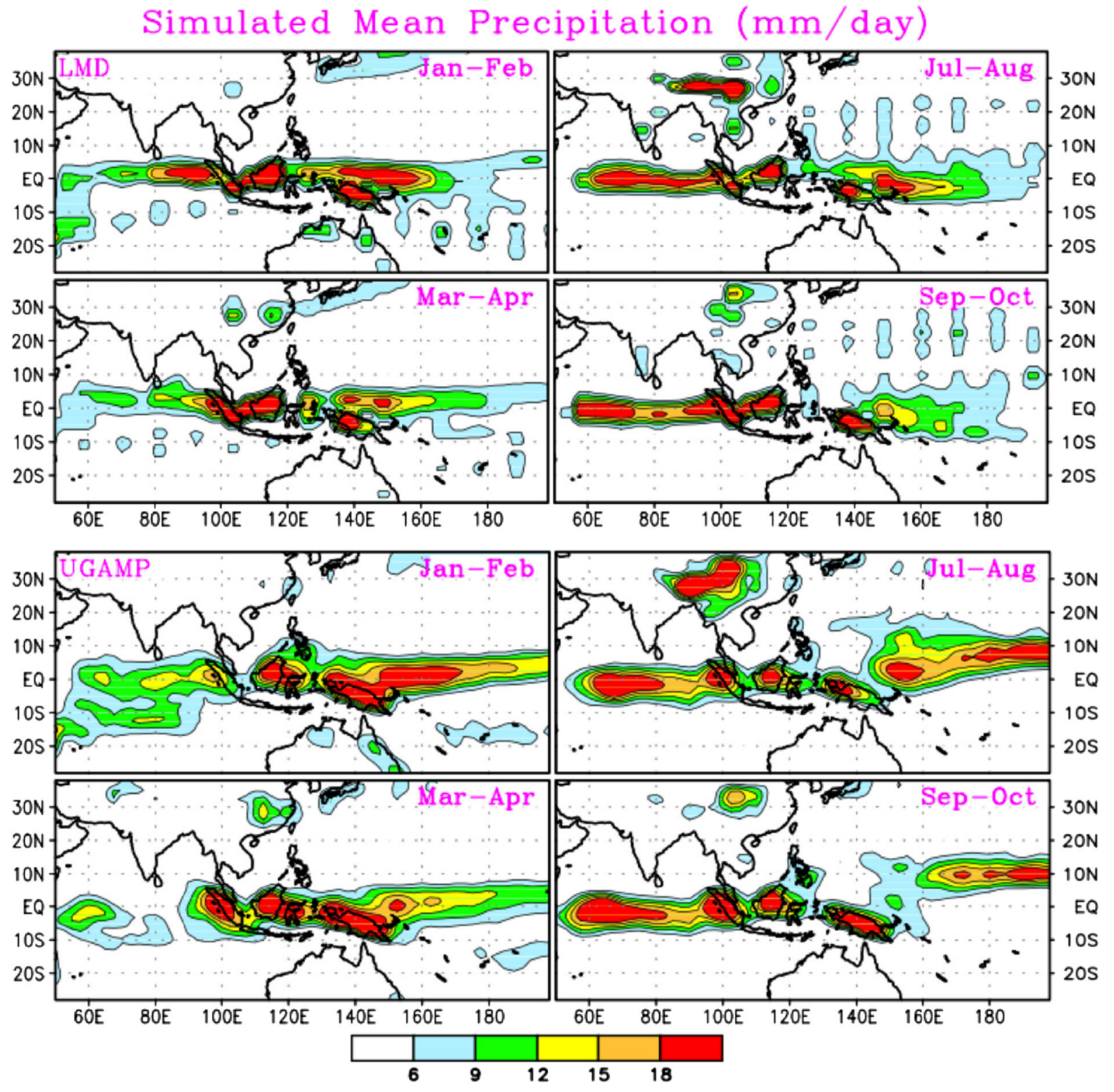

Figure 21. Mean precipitation simulated for January-February, March-April, July-August and September-October in the AMIP runs of the LMD and UGAMP models (after Sajani 1999).

(ii) northward propagations of the oceanic ITCZ. Thus, intraseasonal variation plays an important role in determining the monthly/seasonal patterns over this region.

Clearly, the identification of the basic system responsible for the Indian summer monsoon as the ITCZ has important implications. In Blanford's words "This view ... will be found greatly to facilitate the comprehension of many characteristics of the monsoon, such as its oscillation and those wellknown vicissitudes in the rainfall of India."

That the Indian/South Asian monsoon is a manifestation of the seasonal migration of the ITCZ is now accepted by several scientists. In a recent review of the migrations and dynamics of the ITCZ, Schneider et al. (2014) state 'Over the Indian Ocean and adjacent land surfaces, the ITCZ swings more dramatically between average latitudes of $20^{\circ} \mathrm{N}$ in boreal summer and $8^{\circ} \mathrm{S}$ in boreal winter, prompting the seasonal rainfall variations of the South Asian Monsoon". They point out that "the seasonal ITCZ migration features abrupt and large shifts in the South Asian monsoon sector marking the onset and retreat of the summer monsoon' as seen in figure 20(b) for the Indian longitudes $70^{\circ}-90^{\circ} \mathrm{E}$. Schneider et al. (2014) further state that "the ITCZ neither simply follows the insolation maximum, nor the sinusoidal seasonal 
(a)
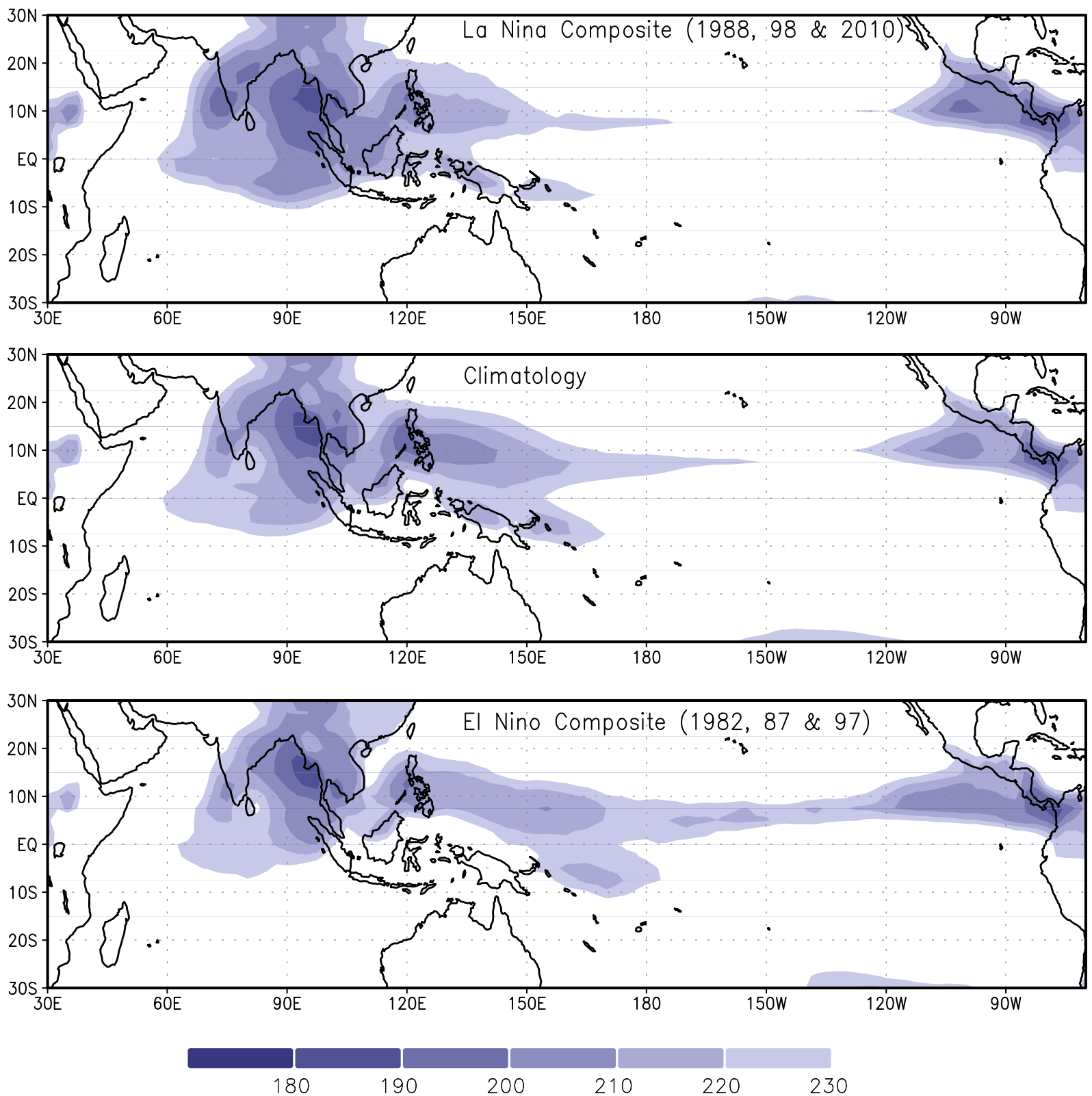

Figure 22. (a) June-September OLR composites for La Nina events of 1988, 1998 and 2010 (top), El Nino events of 1982 , 1987 and 1997 (bottom). The mean June-September OLR is shown in the middle. (b) Correlation of ISMR with JuneSeptember rainfall over the Indian region based on IMD grid data.

variations of the interhemispheric temperature contrast. What mechanisms control the position of the ITCZ and its rainfall intensity is an important unanswered question in climate dynamics." It is interesting that in early versions of some atmospheric general circulation models, the ITCZ did not shift to the Indian subcontinent during the boreal summer but remained, instead, over the warm equatorial Indian Ocean (figure 21, Sajani 1999). Analysis of the factors that led to a transition to a more realistic simulation of the ITCZ over the Indian region in the later versions, would give an insight into this critical issue.

\section{Implications for the Indian summer monsoon and its variability}

The summer monsoon (June-September) is generally referred to as the 'Southwest Monsoon' and the post-monsoon (October-December) as the 'Northeast Monsoon' on the basis of the direction of the surface winds in these two seasons. 


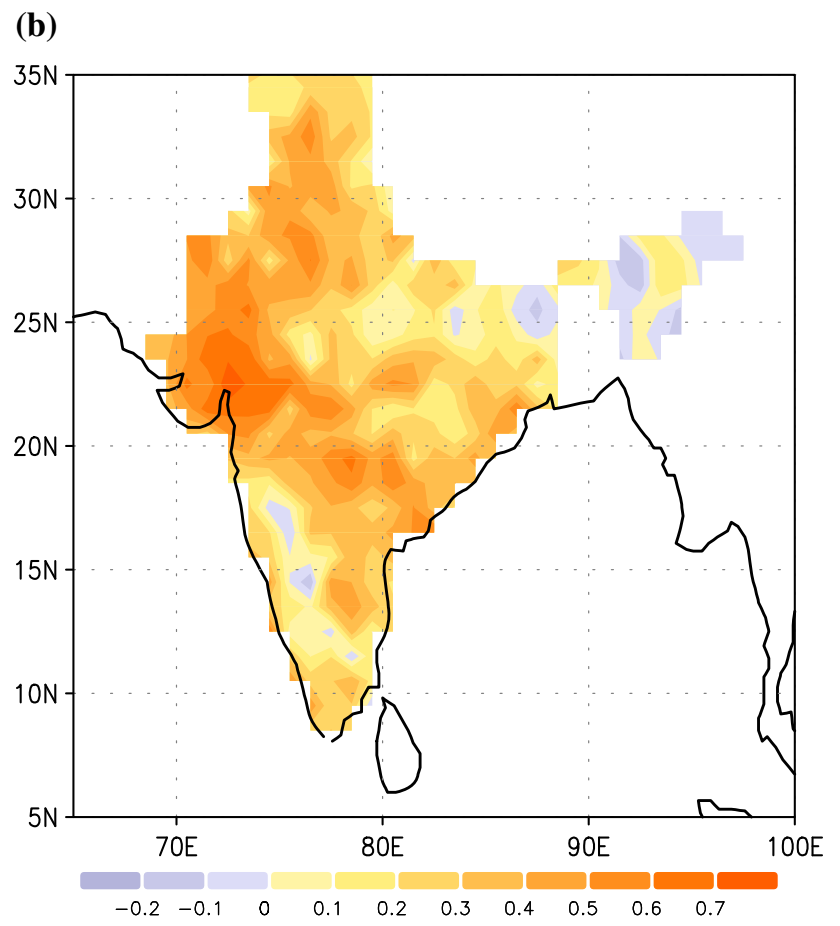

Figure 22. (Continued.)

However, these names appear to give the impression that (i) the systems that give rain in the two seasons are different and further that (ii) the rain comes from the southwest during the 'Southwest Monsoon' and from the northeast during the 'Northeast Monsoon'. In fact, the basic system responsible for the monsoon in both the seasons is the ITCZ (Gadgil 2003) and most of the rainfall over the land during each of the seasons comes from propagation of the cloud systems generated over the surrounding warm ocean (Bay of Bengal, Arabian Sea and the equatorial Indian Ocean) onto the subcontinent. Hence, rather than the popular names 'Southwest Monsoon' and 'Northeast Monsoon' for the two seasons, the terms summer monsoon and post-monsoon should be used.

The most important implication of the attribution of the large-scale monsoon rainfall to the ITCZ, is that the variability of the monsoon will be determined by processes which lead to variability of oceanic ITCZs (e.g., cloud heating of midtroposphere leading to a decrease in CAPE, etc.), as well as processes special to the continental ITCZ such as land surface processes (CTCZ Science plan 2008). Since the ITCZ over the Indian region often extends eastward over the West Pacific and is maintained by northward propagations of the ITCZ over the equatorial Indian Ocean, we expect interactions with the ITCZ over these regions to also play a role in the variability of the Indian summer monsoon on intraseasonal and interannual scales.

Consider the variation of the monsoon on the interannual scale. It is well known that the strong link between the Indian summer monsoon rainfall and ENSO, with a high propensity of droughts (excess rainfall seasons) during El Nino (La Nina), plays a critical role in the interannual variation of the Indian summer monsoon rainfall (Gadgil et al. 2007 and references therein). The composite JuneSeptember OLR patterns over the Asia-Pacific region for El Nino, La Nina and the mean JuneSeptember pattern are shown in figure 22(a). It is seen that in association with a coherent ITCZ stretching across the Pacific during El Nino, the ITCZ over the Indian region does not extend as far westward, as in the case of La Nina, suggesting that the ENSO linked variability is associated with variability of the east-west extent of the ITCZ over the Indian region. If we consider the mean summer monsoon rainfall (figure 5), over the monsoon zone, the rainfall decreases westward/northwestward from the eastern boundary along the Bay and is rather small in the northwestern region adjoining the Thar desert. Variation of the correlation of ISMR with June-September rainfall over the Indian region, depicted in figure $22(\mathrm{~b})$, shows that most of the contribution to the interannual variability of ISMR comes from the variability of the rainfall over the western end of the monsoon zone. The area of the arid region in the northwestern parts changes from year to year. Generally during droughts, the arid area expands eastward as the east-west extent of the CTCZ shrinks, while in excess monsoon seasons the east-west extent of the CTCZ increases and the arid area shrinks (Singh et al. 1992). Thus, for understanding the interannual variability of the monsoon, in addition to unravelling the mechanisms that control the latitudinal location of the ITCZ and its rainfall intensity (Schneider et al. 2014), unravelling those that control the east-west extent of the ITCZ, particularly over the subcontinent is important.

\section{Monsoonal regions of the world}

We have seen that the large-scale rainfall of the Indian summer monsoon is associated with an 
(a)
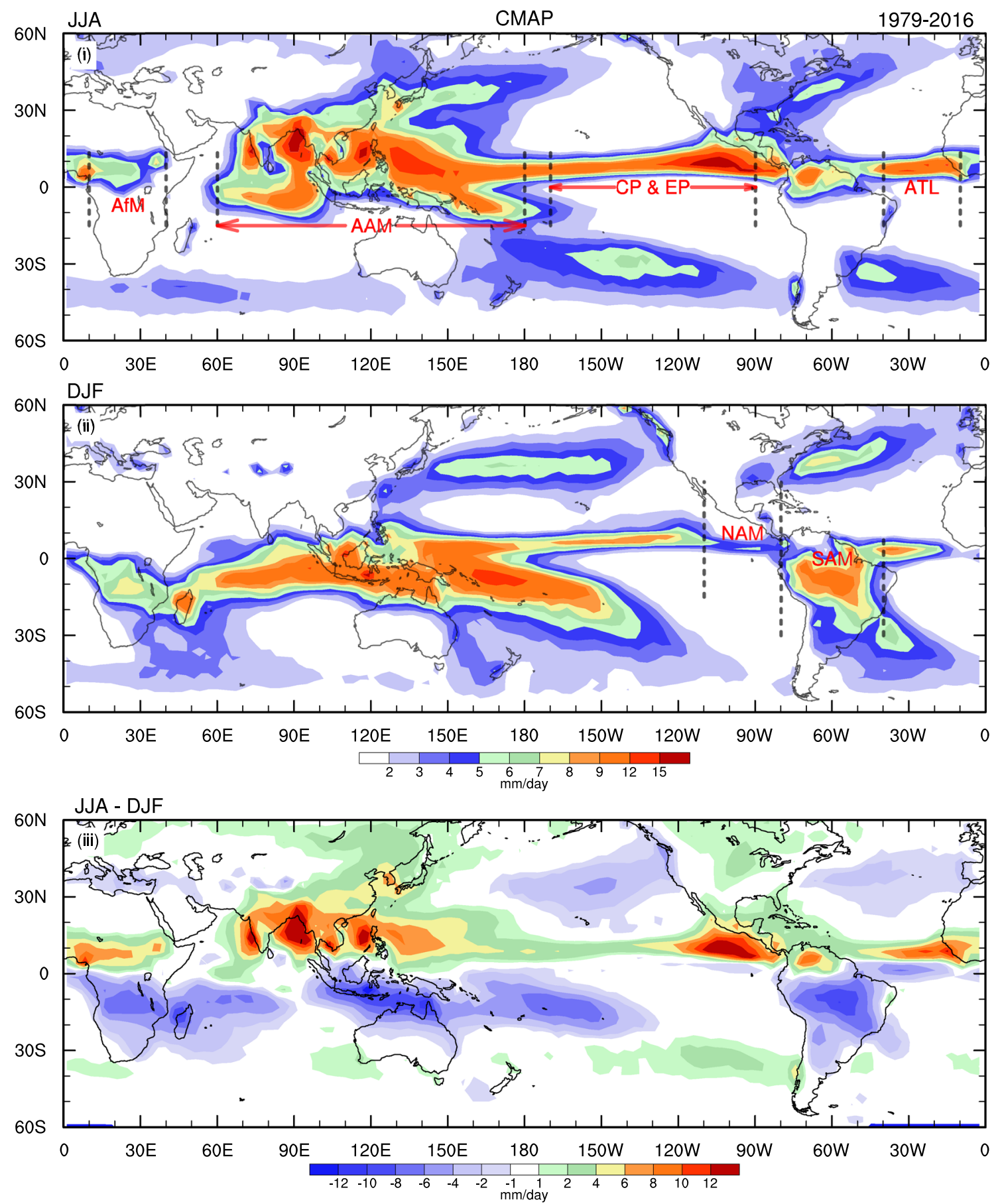

Figure 23. (a) Mean CMAP precipitation for (i) JJA, (ii) DJF and (iii) the difference in the mean precipitation of JJA and DJF. The longitudinal boundaries of the Asian-Australian monsoon (AAM), central and eastern Pacific (CP\&EP) are indicated in the top panel and of North American (NAM) and South American monsoon (SAM) in the middle panel. (b) Variation of the mean monthly precipitation (top) and mean vertical circulation for January and July (bottom) for the sectors Asia-Australia $\left(60^{\circ}-180^{\circ} \mathrm{E}\right)$ (left), and Africa $\left(10^{\circ}-40^{\circ} \mathrm{E}\right)$ (right). (c) Variation of the mean monthly precipitation (top) and mean vertical circulation for January and July (bottom), for the sectors South America $\left(80^{\circ}-40^{\circ} \mathrm{W}\right)$ (left) and North America $\left(110^{\circ}-80^{\circ} \mathrm{W}\right)$ (right).

ITCZ that occurs over the heated subcontinent during the boreal summer as a result of northward migration of the ITCZ occurring over the southern equatorial Indian Ocean in the boreal winter. Thus, the major characteristics of the Indian summer monsoon are: (i) the occurrence of an ITCZ with 
(b)
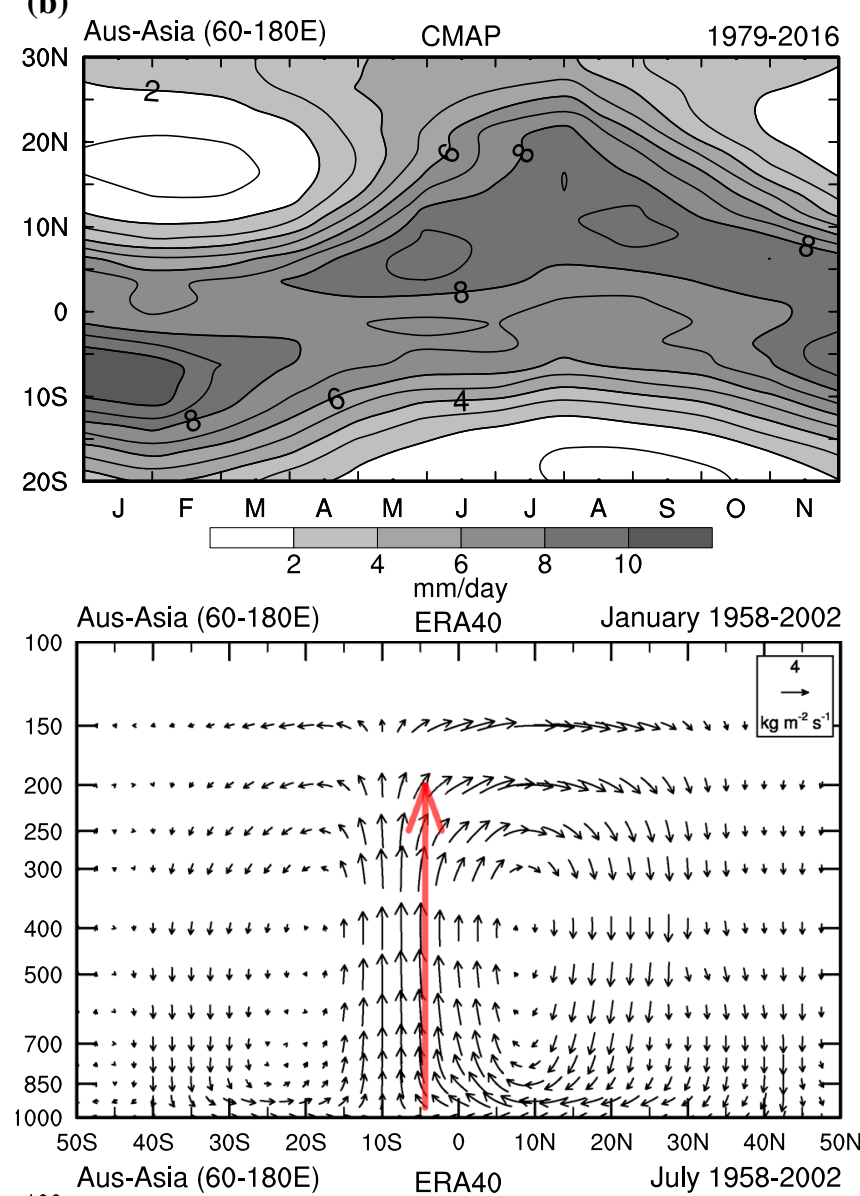

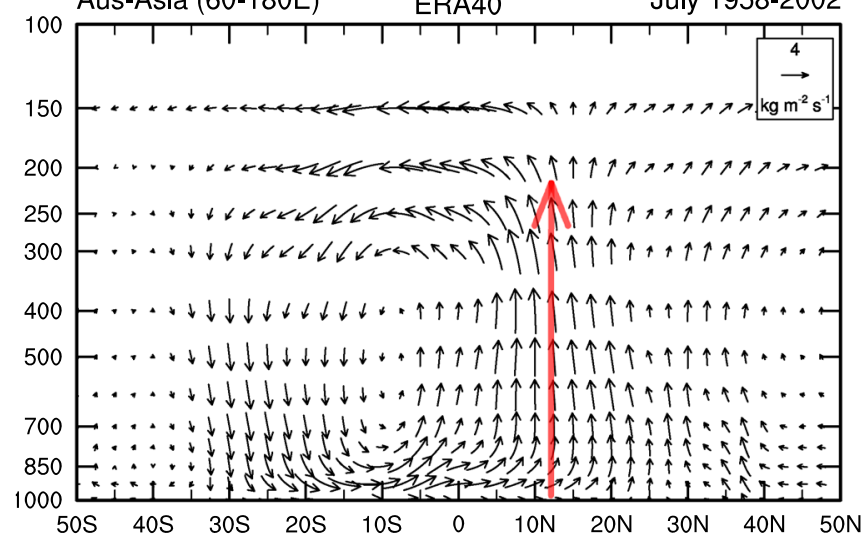

Figure 23.
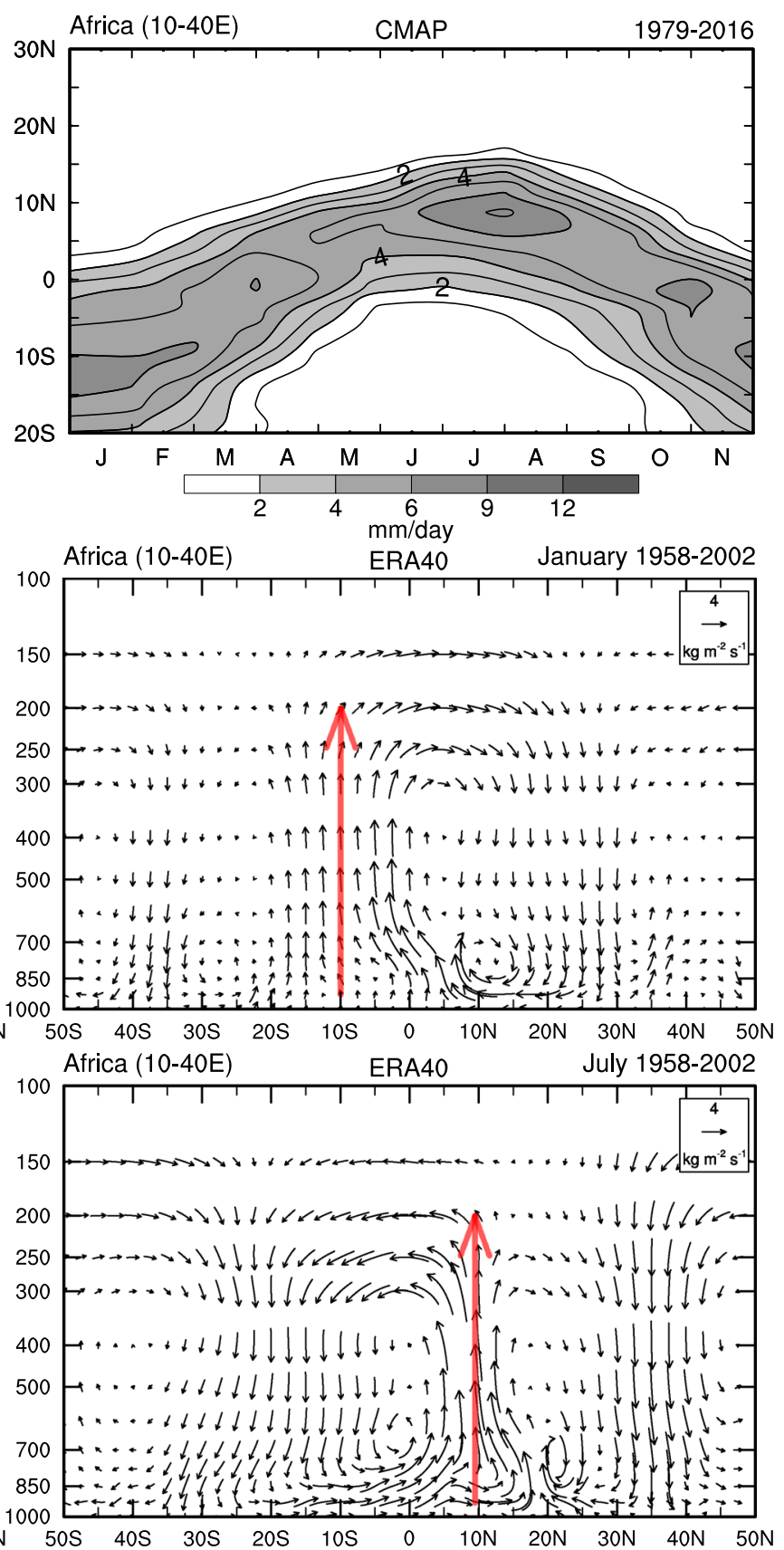

(Continued.)

strong ascent throughout the troposphere over the subcontinent (the CTCZ) during the summer monsoon season (ii) which is a result of a northward migration of the ITCZ occurring over the southern equatorial Ocean in the boreal winter as seen clearly in the (iii) reversal of the overturning circulation from winter to summer. I consider these features as the distinguishing attributes of the monsoon, and identify the monsoonal regions of the world as parts of the tropics over which these features are observed.
The mean rainfall during the northern hemispheric summer (June-August) and southern hemispheric summer (December-February) over the entire tropical belt is shown in figure 23(a), in which the difference in the rainfall of these seasons is also depicted. A large shift in the latitude of the rain-belt with season, from one hemisphere to the other, is seen over the African and Asian-Australian monsoonal regions identified by Ramage (1971) on the basis of seasonal variation in the wind-direction. On the other 

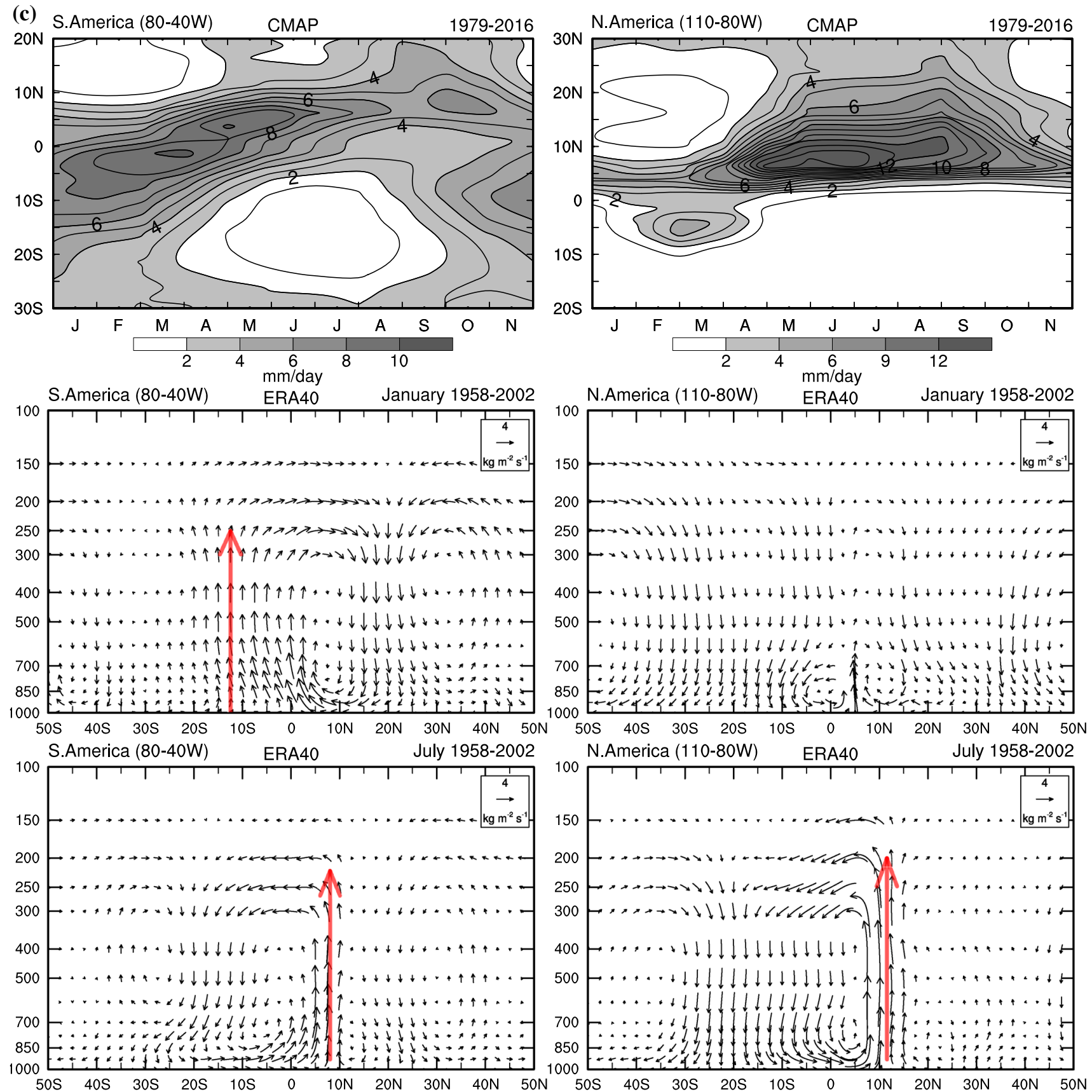

Figure 23. (Continued.)

hand, over the Atlantic, the rainbelt shifts from around $0^{\circ}-3^{\circ} \mathrm{N}$ in the boreal winter to $5^{\circ}-10^{\circ} \mathrm{N}$ in the boreal summer, whereas over the central and east Pacific, the rainbelt hardly shifts with the season but weakens considerably in the boreal winter.

The variation of the mean monthly rainfall during the year averaged over the longitudes characterizing African and Asian-Australian regions (indicated in figure 23a) depicted in figure 23(b) clearly shows migration of the rainbelt between the southern and northern hemispheres over a latitudinal range of about $20^{\circ}$. The vertical circulation over the Asian-Australian longitudes (figure 23b) also shows the presence of an ITCZ with strong ascent throughout the troposphere over $5^{\circ}-20^{\circ} \mathrm{N}$ in the northern summer and over $0^{\circ}-15^{\circ} \mathrm{S}$ in the northern winter. Over the African longitudes, the ITCZ shifts from around $5^{\circ}-15^{\circ} \mathrm{S}$ in the winter to around $10^{\circ} \mathrm{N}$ in the summer (figure $23 \mathrm{~b}$ ). Furthermore, the vertical circulation depicted in figure $23(\mathrm{~b})$ for these regions is similar to the case 
of the Indian monsoon (figure 20c), with a reversal in the overturning circulation with seasons (Trenberth et al. 2006), and hence these regions can be considered as monsoonal regions. Thus, the AsianAustralian monsoon and the African monsoon are also seen to be manifestations of the seasonal variation of the ITCZ.

Webster et al. (1998) have suggested that the Americas qualify as monsoon regions at least in terms of the precipitation. The variation of the mean monthly rainfall during the year and the vertical circulation averaged over the longitudes characterizing the South American longitudes (indicated in figure 23a) are depicted in figure 23(c). Note that, the rainbelt over the South American region is also associated with strong ascent throughout the troposphere, i.e., an ITCZ in both the seasons and reversal of the overturning circulation with season is clearly seen. Zhou and Lau (1998) have made a convincing case for considering this region as monsoonal (although it was not included in Ramage (1971) monsoonal regions of the world, based on seasonal variation of the direction of the wind) by showing that it has two important characteristics, viz., seasonal migration of the rainbelt and cross equatorial flow. Clearly the South American region must also be considered as a monsoonal region on the basis of the criteria used here.

It has been suggested that there is a North American monsoon as well (Webster 1987a; Adams and Corie 1997). The variation of the monthly rainfall and the winter and summer vertical circulation over longitudes corresponding to the North American monsoon (Trenberth et al. 2006) depicted in figure 23(c) shows that in the boreal summer, the rainbelt is associated with a convergence zone with ascent throughout the troposphere, with the axis around $10^{\circ} \mathrm{N}$. There is considerable rainfall northward of the axis up to about $20^{\circ} \mathrm{N}$ and some rain even northward of that. However, over the North American longitudes and East Pacific, the ITCZ occurs only in the boreal summer as an eastward extension of the ITCZ over the Pacific (figure 23a). In the boreal winter, there is only shallow convection and very little rain. Thus, unlike the monsoonal regions discussed so far, the rainfall over the North American region during the summer is not associated with the migration of the ITCZ from the southern hemisphere. Hence, on the basis of the criteria used here for the important characteristics of the rainfall over the monsoonal regions, the North American region cannot be considered to be a monsoonal region.

Thus, if monsoonal regions are characterized by (i) a migration of the rainbelt back and forth across the equator with season, (ii) the large scale rainfall associated with a tropical convergence zone with ascent throughout the troposphere, and (iii) reversal of the overturning circulation with season, the monsoonal regions of world comprise the African, Asian-Australian and South American regions. There will necessarily be some common elements in the variability of the monsoon over these regions. However, we expect differences in the land configurations, orographic features and the oceans around these regions will lead to differences as well. They should help us understand better, the role of each important factor and hence improve our models for simulation and prediction of the monsoon.

\section{Summary and conclusions}

We have tested the hypothesis that the monsoon is a gigantic land-sea breeze driven by the land-ocean contrast in temperature. This hypothesis implies that a summer monsoon season with a much higher (lower) rainfall than the average, will be associated with a stronger (weaker) gradient of temperature between land and ocean. However, Kothawale and Rupa Kumar (2002) had shown that the anomaly of the observed air temperature over the Indian land surface is negative (positive) for large positive (negative) anomalies of monsoon rainfall. Our analysis of the NCEP reanalysis temperature data at $5 \mathrm{~m}$ above land (ALS) and ocean (AOS) also show that the ALS is significantly negatively correlated with the monsoon rainfall. The relationship of the monsoon rainfall with the temperature difference between land and ocean (ALS-AOS) is somewhat weaker, but again stronger monsoons are found to be associated with a weaker land-ocean contrast. This is consistent with the result of the analysis of land-ocean temperatures at $850 \mathrm{hPa}$ and South Asian Summer Monsoon index by Walker et al. (2015). Thus, this popular perception of the monsoon as a gigantic land-sea breeze, which is not only still mentioned in text books and reviews but also used to deduce the expected monsoon variability from the expected land-ocean contrast in some studies, is not supported by observations of the variability of the monsoon and needs to be abandoned. 
An alternative theory according to which the basic system responsible for the monsoon is the ITCZ or equatorial trough is then examined. The system responsible for the large-scale monsoon rainfall over the Indian region is shown to have all the important dynamical characteristics of the ITCZ. It is further shown that the occurrence of the ITCZ over the Indian monsoon zone during the summer monsoon is a result of the seasonal migration of the ITCZ which occurs over the southern equatorial Indian Ocean in the boreal winter. Thus, there is a reversal of the vertical circulation over the Indian longitudes with season, that the Indian/South Asian monsoon is a manifestation of the seasonal migration of the ITCZ is now accepted by several scientists (e.g., Schneider et al. 2014). Clearly, monsoon variability will be linked to the space-time variation of the ITCZ over the subcontinent. The unravelling of the mechanisms that control the latitudinal location of the ITCZ and its rainfall intensity, which has been recognized as an important unanswered question in climate dynamics (Schneider et al. 2014) is important for monsoon dynamics as well. Also, for understanding the variability of the Indian monsoon and its teleconnections, it is important to unravel mechanisms that determine the east-west extent of the ITCZ over the Indian region, i.e., of the CTCZ.

An important implication of the attribution of the large-scale monsoon rainfall to an ITCZ, is that the variability of the monsoon will be determined by processes which lead to variability of oceanic ITCZs (e.g., cloud heating of mid-troposphere leading to a decrease in CAPE, etc.), as well as processes special to CTCZ such as land surface processes (CTCZ Programme Science plan 2008).

If the major characteristics of the Indian summer monsoon, viz., (i) the occurrence of an ITCZ with strong ascent throughout the troposphere over the subcontinent during the summer monsoon season which is a result of (ii) the seasonal migration of the ITCZ occurring over the southern equatorial Indian Ocean in the winter and (iii) reversal of the overturning circulation from winter to summer, are considered to be distinguishing attributes of the monsoon, it is shown that the Asia-Australia region, the African region (which are parts of the monsoonal region identified by Ramage 1971) as well as the South American region comprise the monsoonal regions of the world.

\section{Acknowledgements}

It is a pleasure to acknowledge the monsoon experts, the late D R Sikka, Drs T N Krishnamurti and P V Joseph, from whom I have learnt a great deal, stimulating discussions over many years with Profs J Srinivasan, G S Bhat, Ravi Nanjundiah and other colleagues at CAOS and insights gained from comments of Profs Mark Cane and S G H Philander, contributed significantly to my understanding of the monsoon problem. This paper could not have been written without the fruitful interaction with Drs P A Francis, Sajani Surendran and K Rajendran. A detailed and careful review by Dr D Shankar and useful suggestions by the reviewers helped considerably in improving the paper.

\section{References}

Adams D K and Corie A C 1997 The North American monsoon; Bull. Am. Meteorol. Soc. 78 2197-2213.

Adler R F, Huffman G J, Chang A, Ferrar R, Xie P, Janowiak J, Rudolf B, Schneider U, Curtis S, Bolvin D, Gruber A, Susskind J and Arkin P 2003 The Version 2 Global Precipitation Climatology Project (GPCP) Monthly Precipitation Analysis (1979-Present); J. Hydrometeor. 4 1147-1167.

Anjaneyulu T S S 1969 On the estimates of heat and moisture over the Indian monsoon trough zone; Tellus 21(1) $64-75$.

Bhat G S 2002 Near-surface variations and surface fluxes over the northern Bay of Bengal during the 1999 Indian summer monsoon; J. Geophys. Res. 107(D17) 4336, https:// doi.org/10.1029/2001JD000382.

Bhat G S et al. 2001 BOBMEX - The Bay of Bengal Monsoon Experiment, Bull. Am. Meteor. Soc. 822217 2243.

Blandford H F 1886 Rainfall of India; Monsoon Monograph - India Meteorological Department, No. 3, 658.

Charney J G 1969 The intertropical convergence zone and the Hadley circulation of the atmosphere; Proc. WMO/IUCG Symp. Numer. Weather Predict, Jpn. Meteorol. Agency III 73-79.

Continental Tropical Convergence Zone (CTCZ) programme Science plan 2008, Department of Science and Technology, Government of India, ISBN 978-81-7525-997-3.

Ding Y and Sikka D R 2006 Synoptic systems and weather; In: The Asian Monsoon (ed.) Bin Wan, Springer.

Gadgil Sulochana 1988 Recent advances in monsoon research with particular reference to the Indian monsoon; Aust. Meteorol. Mag. 36 193-204.

Gadgil Sulochana 2003 The Indian monsoon and its variability; Ann. Rev. Earth. Planet. Sci. 31 429-467.

Gadgil Sulochana and Gadgil Siddhartha 2006 The Indian monsoon, GDP and agriculture; Economic and Political Weekly XLI(47) 4887-4895.

Gadgil Sulochana, Seshagiri Rao P R and Narahari Rao K 2002 Use of climate information for farm-level decision 
making: Rainfed groundnut in southern India; Agricultural Systems $\mathbf{7 4}$ 431-457.

Gadgil Sulochana, Rajeevan M and Francis P A 2007 Monsoon variability: Links to major oscillations over the equatorial Pacific and Indian oceans; Curr. Sci. 93(2) 182-194.

Hadley 1735 G Concerning the cause of the general trade winds; Phil. Trans. Roy. Soc. 34 (1735) 58-62.

Halley E 1686 A historical account of the trade winds and monsoons observable in the seas between and near the tropics with an attempt to assign a physical cause of the said winds; Phil. Trans. Roy. Soc. London 16 153-168.

IPCC Climate Change 2013 The Physical Science Basis; Contribution of Working Group I to the Fifth Assessment Report of the Intergovernmental Panel on Climate Change (eds) Stocker T F et al., Cambridge University Press, 1535p.

James I N 1994 Introduction to circulating atmospheres; Cambridge University Press.

Jin Q and Wang C 2017 A revival of Indian summer monsoon rainfall since 2002; Nature Climate Change 7 587-594.

Kalnay E et al. 1996 The NCEP/NCAR 40-year reanalysis project; Bull. Am. Meteor. Soc. 2 437-471.

Kothawale and Rupa Kumar 2002 Tropospheric temperature variation over India and links with the Indian summer monsoon: 1971-2000; Mausum 53 289-308.

Lau W and Li M T 1984 The monsoon of East Asia and its global associations - A survey; Bull. Am. Meteor. Soc. 65 114-125, https://doi.org/10.1175/ 1520-0477(1984)065〈0114:TMOEAA $>2.0 . \mathrm{CO} ; 2$.

Lau W and Kim M K 2017 Competing influences of greenhouse warming and aerosols on Asian summer monsoon circulation and rainfall; Asia-Pac. J. Atmos. Sci. 53(2) 181-194.

Li C and Yanai M 1996 The onset and interannual variability of the Asian summer monsoon in relation to land-sea thermal contrast; J. Climate 9 358-375, https://doi.org/ 10.1175/1520-0442(1996)009〈0358:TOAIVO〉.2.0.CO;2.

Liebmann B 1996 Description of a complete (interpolated) outgoing long wave radiation dataset; Bull. Am. Meteor. Soc. 77 1275-1277.

Meehl G A 1992 Effect of tropical topography on global climate; Ann. Rev. Earth Planet. Sci. 20 85-112.

Murakami M 1987 Satellite cloudiness in the monsoon area in monsoon meteorology (eds) Chang $\mathrm{C} \mathrm{P}$ and Krishnamurti T N, Oxford University Press, New York, 359 p.

Parthasarathy B, Munot A A and Kothawale D R 1994 All-India monthly and seasonal rainfall series: 1871-1993; Theor. Appl. Climatol. 49(4) 217-224.

Raghavan K 1973 Break monsoon over India; Mon. Wea. Rev. $10133-43$.

Rajeevan M, Bhate J, Kale K D and Lal B 2006 High resolution daily gridded rainfall data for the Indian region: Analysis of break and active monsoon spells; Curr. Sci. 91 296-306.

Ramage C S 1971 Monsoon Meteorology; Int. Geophys. Ser., Vol. 15, San Diego, CA: Academic.

Rao Y P 1976 Southwest Monsoon; Meteorological Monograph (synoptic meteorology), No. 1, India Meteorological Department, New Delhi, 366p.
Rayner N A, Parker D E, Horton E B, Folland C K, Alexander L V, Rowell D P, Kent E C and Kaplan A 2003 Global analyses of sea surface temperature, sea ice, and night marine air temperature since the late nineteenth century; J. Geophys. Res. 108(D14) 4407, https://doi. org/10.1029/2002JD002670.

Riehl H 1954 Tropical Meteorology; McGraw Hill, New York, $392 \mathrm{p}$.

Riehl H 1979 Climate and Weather in the Tropics; Academic Press, San Diego, New York, 611p.

Sajani Surendran 1999 Simulation of monsoon precipitation and its variation by atmospheric general circulation models; Ph.D. thesis, Indian Institute of Science, Bangalore, India.

Schneider T, Bischoff T and Haug G H 2014 Migrations and dynamics of the intertropical convergence zone; Nature 513 45-53, https://doi.org/10.1038/nature13636.

Sikka D R and Sulochana Gadgil 1980 On the maximum cloud zone and the ITCZ over India longitude during the southwest monsoon; Mon. Wea. Rev. 108 1840-1853.

Simpson G 1921 The south-west monsoon; Quart. J. Roy. Meteorol. Soc. 199(17) 150-173.

Singh N, Pant G B and Mulye S S 1992 Spatial variability of aridity over northern India; Proc. Indian Acad. Sci. (Earth Planet. Sci.) 101(3) 201-213.

Srinivasan J 2011 Response of a fluid to differential heating from below; Personal communication.

Srivastava A K, Rajeevan M and Kshirsagar S R 2008 Development of a high resolution daily gridded temperature data set (1969-2005) for the Indian region; National Climate Centre, India Meteorological Department, Pune, Research Report No: 8/2008.

Trenberth K E, Stepaniak D P and Caron J M 2000 The global monsoon as seen through the divergent atmospheric circulation; J. Climate 12 3969-3992.

Trenberth K E, Hurrell J W and Stepaniak D P 2006 The Asian Monsoon: Global perspectives; In: The Asian Monsoon (ed.) Bin Wang, Springer.

Uppala S M, KÅllberg P W, Simmons A J, Andrae U, Bechtold V D C, Fiorino M, Gibson J K, Haseler J, Hernandez A, Kelly G A, Li X, Onogi K, Saarinen S, Sokka N, Allan R P, Andersson E, Arpe K, Balmaseda M A, Beljaars A C M, Berg L V D, Bidlot J, Bormann N, Caires S, Chevallier F, Dethof A, Dragosavac M, Fisher M, Fuentes M, Hagemann S, Hólm E, Hoskins B J, Isaksen L, Janssen P A E M, Jenne R, Mcnally A P, Mahfouf J-F, Morcrette J-J, Rayner N A, Saunders R W, Simon P, Sterl A, Trenberth K E, Untch A, Vasiljevic D, Viterbo P and Woollen J 2005 The ERA-40 re-analysis; Quart. J. Roy. Meteorol. Soc. 131 2961-3012, https://doi.org/10.1256/qj.04.176.

Walker J M, Bordoni S and Schneider T 2015 Interannual variability in the large-scale dynamics of the south Asian summer monsoon; J. Climate 283731.

Webster P J 1987a The elementary monsoon; In: Monsoons (eds) Fein $\mathrm{J}$ and Pamela Stephens, WileyInterscience.

Webster P J 1987b The variable and interactive monsoon; In: Monsoons (eds) Fein J and Pamela Stephens, WileyInterscience.

Webster P J, Magaña V O, Palmer T N, Shukla J, Tomas R A, Yanai M and Yasunari T 1998 Monsoons: Processes, 
predictability and the prospects for prediction; J. Geophys. Res. 103 14,451-14,510.

Xie P and Arkin P A 1997 Global precipitation: A 17-year monthly analysis based on gauge observations,satellite estimates, and numerical model outputs; Bull. Am. Meteor. Soc. 78 2539- 2558.

Zhou J and Lau K M 1998 Does the monsoon climate exist over South America; J. Climate 111020.

Corresponding editor: N V ChALAPATHI RAO 